\title{
A fuzzy group Electre method for electronic supply chain management framework selection
}

\author{
Faramak Zandi ${ }^{\mathrm{a}}$, Madjid Tavana ${ }^{\mathrm{b}} *$ and David Martin ${ }^{\mathrm{c}}$ \\ ${ }^{a}$ Industrial Engineering Department, Alzahra University, Vanak, Tehran 19938-91176, Iran; \\ ${ }^{b}$ Management Information Systems, La Salle University, Philadelphia, PA 19141, USA; ${ }^{c}$ Ronald L. Bittner \\ School of Business, St. John Fisher College, Rochester, New York 14618, USA
}

(Received 7 January 2010; final version received 30 September 2010)

\begin{abstract}
The rapid growth of the Internet and electronic commerce has given rise to electronic supply chain management (e-SCM) which enhances communication, coordination, and collaboration between the trading partners. However, when confronted by the range of e-SCM frameworks, organisations struggle to identify the one most appropriate to their needs. In this paper, we propose a novel fuzzy group multi-criteria method for e-SCM framework evaluation and selection. The contribution of the proposed method is fourfold: (1) it addresses the gaps in the SCM literature on the effective and efficient assessment of the e-SCM frameworks; (2) it is grounded in the excellence model introduced by the European Foundation for Quality Management; (3) it provides a comprehensive and systematic framework that combines real options analysis and the analytic hierarchy process with a group Electre method; and (4) it considers fuzzy logic and fuzzy sets to represent ambiguous, uncertain, or imprecise information. We also present the results of a real-world case study to demonstrate the applicability of the proposed framework and exhibit the efficacy of the procedures and the algorithms. We show that the proposed framework can help a group of decision makers to think systematically by decomposing the alternative evaluation process into manageable steps and integrating the results to arrive at a solution consistent with managerial goals and objectives. The analysis of this case study allows for the articulation of a series of key factors that can be considered important in contributing to the successful implementation of the e-SCM framework. The first element is getting the key people on board. The second factor is building internal alliances. The third key ingredient is the persistent and systematic process put in place to evaluate the e-SCM success.
\end{abstract}

Keywords: electronic supply chain management; analytic hierarchy process; Electre method; real options analysis; fuzzy sets and logic; the European Foundation for Quality Management

\section{Introduction}

Electronic supply chain management (e-SCM) is an Internet value-added process that covers both the upstream and the downstream business through which a product travels from raw materials to manufacturing and from manufacturing to marketing (Chorafas 2001). E-SCM is an emerging strategic trend which is gaining momentum. Cagliano et al. (2005) surveyed 338 manufacturing companies in eight countries in Europe and found that $44.6 \%$ of the companies surveyed adopted e-business in their supply chain processes. Although the benefits of e-SCM are numerous and

*Corresponding author. Email: tavana@lasalle.edu

ISSN 1367-5567 print/ISSN 1469-848X online

(C) 2011 Taylor \& Francis

DOI: $10.1080 / 13675567.2010 .550872$

http://www.informaworld.com 
indisputable, indiscriminate use of improper e-SCM frameworks has been costly and detrimental to the business enterprise (Chopra and van Miegham 2000). Problems that arose in the Amazon supply chain (van Hoek 2001) and in the Intel supply chain (Phan 2003) highlight the importance of selecting a suitable e-SCM framework. One of the contributing factors to these unsuccessful stories is the fact that the e-SCM frameworks adopted by Amazon and Intel did not totally embrace the concepts of Internet and SCM (Chopra and van Mieghem 2000, Grieger 2003, Smart 2008). Nevertheless, substantial improvements in efficiency, asset utilisation, and customer service have been achieved by companies that adopt an optimal e-SCM framework (Johnson and Whang 2002).

The recent proliferation of papers about the Internet and SCM explains the ever-increasing interest in e-SCM (Giménez and Lourenço 2008). Johnson and Whang (2002) and Gunasekaran and Ngai (2004b) have classified the e-SCM papers and identified the major issues surrounding the impact of the Internet on SCM. Yin and Khoo (2007) have proposed a hierarchical model for e-supply chain coordination and optimisation, and Chen et al. (2004) have investigated e-supply chain implementation strategies in a transitional economy. Mukhtar et al. (2009) have proposed an e-supply chains simulation framework. In addition to the above-mentioned methods, there is a research study which emphasises on the application of the real options approach to supply chain decisions (Drahovzal 2006).

The increasing complexity in the supply chain systems and the larger number of conflicting criteria have made the e-SCM framework selection a difficult and complex task. The traditional e-SCM framework selection methods overemphasise quantitative and economic analysis and often neglect to consider qualitative and non-economic data in the formal selection process. Furthermore, crisp data are fundamentally indispensable in traditional e-SCM framework selection methods. However, the data in real-world problems are often qualitative, imprecise, and ambiguous. Stockdale and Standing (2002) report on the difficulty faced by organisations in developing strategies in relation to the e-SCM framework selection process. Joo and Kim (2004) iterated that the selection of e-SCM is at best industry-specific. In this paper, we propose a fuzzy Electre method for e-SCM framework selection that takes into consideration: (1) the excellence model introduced by the European Foundation for Quality Management (EFQM); (2) the imprecise or vague judgements which lead to ambiguity in the decision process; and (3) a robust group Electre model to aggregate both qualitative judgements and quantitative data from real options analysis (ROA).

This paper is organised into five sections. We present a comprehensive literature review in Section 2. In Section 3, we illustrate the details of the proposed framework, and in Section 4, we present a case study to demonstrate the applicability of the proposed framework and exhibit the efficacy of the procedures and algorithms. In Section 5, we sum up with our conclusions and future research directions.

\section{Literature review}

Multiple-criteria decision analysis (MCDA) methods provide a formal framework for information exchange among the decision makers (DMs), thus enhancing and structuring the decision-making process. A number of decision methodologies in the group decision-making context have been presented in the MCDA literature. A comprehensive survey can be found in Hwang and Lin (1987). Iz and Gardiner (1993) review formal group decision-making models and describe some examples of conceptual frameworks and actual implementations of group decision-making models. A comprehensive collection of research devoted to synthesis and analysis of group support frameworks and procedures can be found in Jessup and Valacich (1993). When facing such multiple criteria issues, the literature and research show that the following difficulties may be encountered: 
(1) DMs often use verbal expressions and linguistic variables for subjective judgements that lead to ambiguity (Poyhonen et al. 1997). Furthermore, the subjective assessment process is intrinsically imprecise and may involve two types of judgements: comparative judgement and absolute judgement (Saaty 2006).

(2) DMs often provide imprecise or vague information due to lack of expertise, unavailability of data, or time constraints (Kim and Ahn 1999).

(3) Meaningful and robust aggregation of subjective and objective judgements affects the evaluation process (Valls and Torra 2000).

A decision may not be appropriately made without fully considering its context and all criteria in an MCDA (Belton and Stewart 2002, Yang and Xu 2002). Recently, MCDA researchers have focused on models to integrate the intuitive preferences of multiple DMs into structured and analytical frameworks (Bailey et al. 2003, Costa et al. 2003, Hsieh et al. 2004, Tavana 2006, Liesiö et al. 2007). MCDA requires the determination of weights that reflect the relative importance of various competing criteria. Several approaches such as point allocation, paired comparisons, trade-off analysis, and regression estimates could be used to specify these weights (Kleindorfer et al. 1993).

\subsection{The analytic hierarchy process $(\mathrm{AHP})$}

We use the AHP developed by Saaty (1977) to estimate the importance weight of the criteria. The process is simplified by confining the estimates to a series of pairwise comparisons. The measure of inconsistency provided by the AHP allows for the examination of inconsistent priorities. One of the advantages of the AHP is that it encourages DMs to be consistent in their pairwise comparisons. Saaty (1990a) suggests a measure of consistency for the pairwise comparisons. When the consistency ratio is unacceptable, the DMs become aware that their pairwise comparisons are logically inconsistent, and they are prompted to revise them. The AHP has been a very popular technique for determining weights in MCDA (Vaidya and Kumar 2006, Ho 2008, Saaty and Sodenkamp 2008). Another advantage of the AHP is its capability to value criteria and to scale them discriminately using a procedure that measures the consistency of these scale values (Saaty 1989).

There has, though, been some criticism of the AHP in the operations research literature. Harker and Vargas (1987) show that the AHP does have an axiomatic foundation, the cardinal measurement of preferences is fully represented by the eigenvector method, and the principles of hierarchical decomposition and rank reversal are valid. Conversely, Dyer (1990a) has questioned the theoretical basis underlying the AHP and argues that it can lead to preference reversals rather than the best or preferential outcome. In response, Saaty (1990b) explains how rank reversal is a positive feature when new reference points are introduced. In this study, the geometric aggregation rule is used to avoid the controversies associated with rank reversal (Dyer 1990a, 1990b, Harker and Vargas 1990, Saaty 1990b).

\subsection{The Electre method}

Outranking is an MCDA approach in which actions are systematically compared to one another on each criterion. The comparisons between the actions lead to numerical results that show the concordance and/or the discordance between the actions. Outranking methods usually involve two steps (Roy 1991, Roy and Bouyssou 1993). First, the actions are compared pairwise in order to build an outranking relation. In the second step, this outranking relation is exploited in order to propose a recommendation to the DM. The most widely used method in this group is Electre (Roy and Bouyssou 1993). Other similar methods have been proposed by Belacel (2000), Doumpos 
and Zopounidis (2004), and Perny (1998). Recently, some metaheuristics have been proposed for outranking methods. Belacel et al. (2007) used the reduced variable neighbourhood search metaheuristic to deduce the parameters of a fuzzy multi-criteria classification method, called PROAFTN, from a set of reference examples. Goletsis et al. (2004) used a genetic algorithm for the development of an outranking model in a two-group problem involving ischaemic beat classification. The outranking methods as a special subgroup of MCDA methods are particularly suitable for integral decision-making through the notion of weak preference and incomparability, which better represent the real decision situation (Geldermann et al. 2000). Vincke (1992) provides an excellent review of the best-known outranking methods; see also Figueira et al. (2004) for state-of-the-art surveys.

An important advantage of the outranking methods (e.g. Electre methods) is their ability to take ordinal scales into account without converting the original scales into abstract ones with an arbitrary imposed range (Martel and Roy 2006) and at the same time maintain the original verbal meaning (see Greco et al. (2001) for an example of a methodology considering purely ordinal scales). A second advantage of the outranking methods is that indifference and preference thresholds can be considered when modelling imperfect knowledge, which is impossible in the previous mentioned methods. The Electre method and its derivatives have played a prominent role in the group of outranking methods. The main objective in Electre is the proper utilisation of the outranking relations. The outranking methods enable the utilisation of incomplete value information and, for example, judgements on ordinal measurement scale (e.g. Rogers and Bruen 1998).

\subsection{The fuzzy logic}

A pitfall of the Electre method is the need for the precise measurement of the performance ratings and criteria weights (Figueira et al. 2005). However, in many real-world problems, ratings and weights cannot be measured precisely as some DMs may express their judgements using linguistic terms such as low, medium, and high (Zadeh 1975, Chen 2000, Tsaur et al. 2002). The fuzzy set theory is ideally suited for handling this ambiguity encountered in solving Multi-criteria Decision Making (MCDM) problems. Since Zadeh (1965) introduced fuzzy set theory and Bellman and Zadeh (1970) described the decision-making method in fuzzy environments, an increasing number of studies have dealt with uncertain fuzzy problems by applying fuzzy set theory (Yager 1977, Zimmermann 1991). According to Zadeh (1975), it is very difficult for conventional quantification to reasonably express complex situations and it is necessary to use linguistic variables whose values are words or sentences in a natural or artificial language.

\subsection{The ROA}

A review of the current literature offers several technology-based investment evaluation methods that provide frameworks for the quantification of risks and benefits. The net present value, return on investment, cost benefit analysis, information economics, and return on management are among most widely used methods to assess the risks and payoffs associated with technology-based investments. In addition to the above-mentioned traditional quantitative approaches, there is a stream of research studies which emphasises ROA. The ROA differs from the traditional methods in terms of priceability of the underlying investment project (McGrath 1997). With the traditional methods, the underlying investment project of an option is priced as known (Black and Scholes 1973), while in technology-based investment situations, the price of an underlying investment is rarely known (McGrath 1997). The ROA uses three basic types of data: (1) current and possible future investment options, (2) the desired capabilities sought by the organisation, and (3) the 
relative risks and costs of other technology-based investment options that could be used. The method can help assess the risks associated with technology-based investment decisions by taking into consideration the changing nature of business strategies and organisational requirements.

The real options are commonly valued with the Black-Scholes option pricing formula (Black and Scholes 1973). When valuating an investment using ROA, it is required to estimate several parameters (i.e. expected payoffs and costs or investment deferral time). However, the estimation of uncertain parameters in this valuation process is often very challenging. Most traditional methods use probability theory in their treatment of uncertainty. Fuzzy logic and fuzzy sets can represent ambiguous, uncertain, or imprecise information in the ROA by formalising inaccuracy in human decision-making (Collan et al. 2009). For example, fuzzy sets allow for the graduation of belonging in future cash-flow estimation (i.e. future cash flow at year 5 is about 5000 dollars). Fuzzy set algebra developed by Zadeh (1965) is the formal body of theory that allows the treatment of imprecise estimates in uncertain environments.

In recent years, several researchers have combined fuzzy set theory with ROA. Carlsson and Fullér (2003) introduced a (heuristic) real option rule in a fuzzy setting, where the present values of expected cash flows and expected costs are estimated by trapezoidal fuzzy numbers. Chen et al. (2007) developed a comprehensive but simple methodology to evaluate technology-based investments in a nuclear power station based on fuzzy risk analysis and real option approach. Frode (2007) used the conceptual real option framework of Dixit and Pindyck (1994) to estimate the value of investment opportunities in the Norwegian hydropower industry. Villani (2008) combined two successful theories, namely real options and game theory, to value the investment opportunity and the value of flexibility as a real option while analysing the competition with game theory. Collan et al. (2009) presented a new method for real option valuation using fuzzy numbers. Their method considered the dynamic nature of the profitability assessment, that is, the assessment changes when information changes. As cash flows taking place in the future come closer, information changes, and uncertainty is reduced. Chrysafis and Papadopoulos (2009) presented an application of a new method of constructing fuzzy estimators for the parameters of a given probability distribution function using statistical data. Wang and Hwang (2007) developed a fuzzy research and development portfolio selection model to hedge against the environmental uncertainties. They applied fuzzy set theory to model uncertain and flexible project information. Since traditional project valuation methods often underestimate a risky project, a fuzzy compoundoptions model was used to evaluate the value of each project. Their portfolio selection problem was formulated as a fuzzy zero-one integer programming model that could handle both uncertain and flexible parameters and determine the optimal project portfolio. A new transformation method based on qualitative possibility theory was developed to convert the fuzzy portfolio selection model into a crisp mathematical model from the risk-averse perspective. The transformed model was solved by an optimisation technique.

\subsection{The excellence model}

Our approach combines the Electre method with the fuzzy logic of ROA to create a framework to select the optimal e-SCM framework. We use the EFQM excellence model (2009) depicted in Figure 1 as the framework for measuring the strengths and weaknesses of an organisation and provide a holistic framework that systematically addresses a thorough range of organisational quality issues. The EFQM starts with the premise that customer, people, and society results are achieved through leadership which drives strategy, people, partnerships, and resources leading ultimately to excellence in key performance results.

The EFQM has nine elements separated into 'enablers' and 'results'. The enablers demonstrate the efficiency of the organisation's ability to manage its strategy, staff, resources, and key processes. The enablers are: (1) leadership; (2) people; (3) policy and strategy; (4) partnerships and 


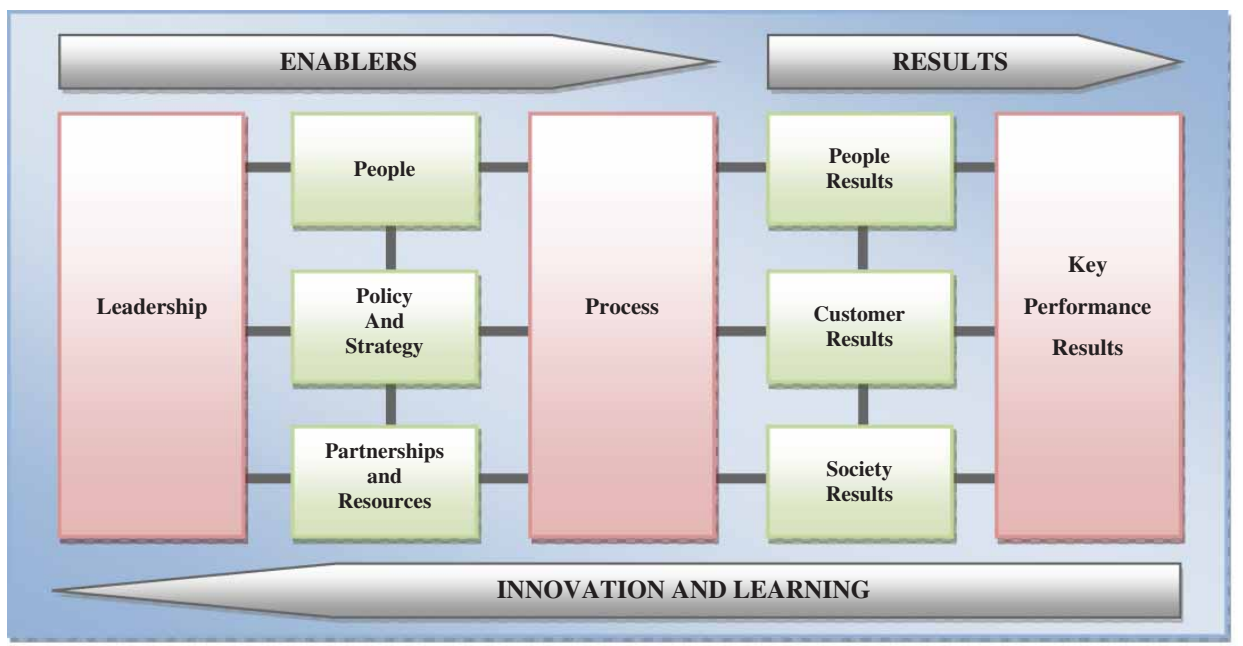

Figure 1. The excellence model framework (created using data from Excellence in view, 2009).

resources; and (5) processes. The EFQM shows that the organisation's results are the level of satisfaction among the employees and customers, the organisation's impact on the wider community, and key performance indicators. The results are: (6) people results; (7) customer results; (8) society results; and (9) key performance results. Each of the nine criteria is further divided into subcriteria to describe in more detail the concept of 'excellence'. The National Council for Voluntary Organizations (NCVO) suggests that each organisation should develop a modified version of the framework that suits them best (Excellence in View 2009).

\section{Proposed framework}

The framework depicted in Figure 2 is proposed to assess the alternative e-SCM frameworks. A description of the mathematical notations and definitions used in the proposed framework is provided in Appendix 1. The framework consists of several phases, processes, and steps.

A common group decision-making activity is evaluating and deciding upon various alternatives (Ngwenyama and Brysona 1999). Decision-making groups in organisations are often formed as committees to evaluate decision alternatives by collecting and synthesising information from different perspectives. Committee decision-making is an effective way to overcome judgement errors in organisations due to human fallibility (Koh 1994). Maier (2010) summarises the virtues of committee decision-making as follows: first, if every committee member exerts effort to become informed, committees can gather more information than individual members. Better information can lead to better decisions. Second, if all committee members have the same information, they may not reach the same conclusion since committee members typically have different backgrounds and experiences. Third, if some information is erroneous, a committee can pool signals and reduce uncertainty. Fourth, committees provide an insurance against extreme preferences of individual DMs.

We propose establishing a committee of informed individuals to pool expertise from many domains. In our framework, we refer to this committee as the 'steering committee (SC)'. In addition, several temporary decision bodies are formed throughout the evaluation process to tackle the ad hoc aspects of the problem. These decision bodies comprise the SC members and are referred to as the 'provisional committees (PCs)'. Finally, we form a specialised committee responsible 


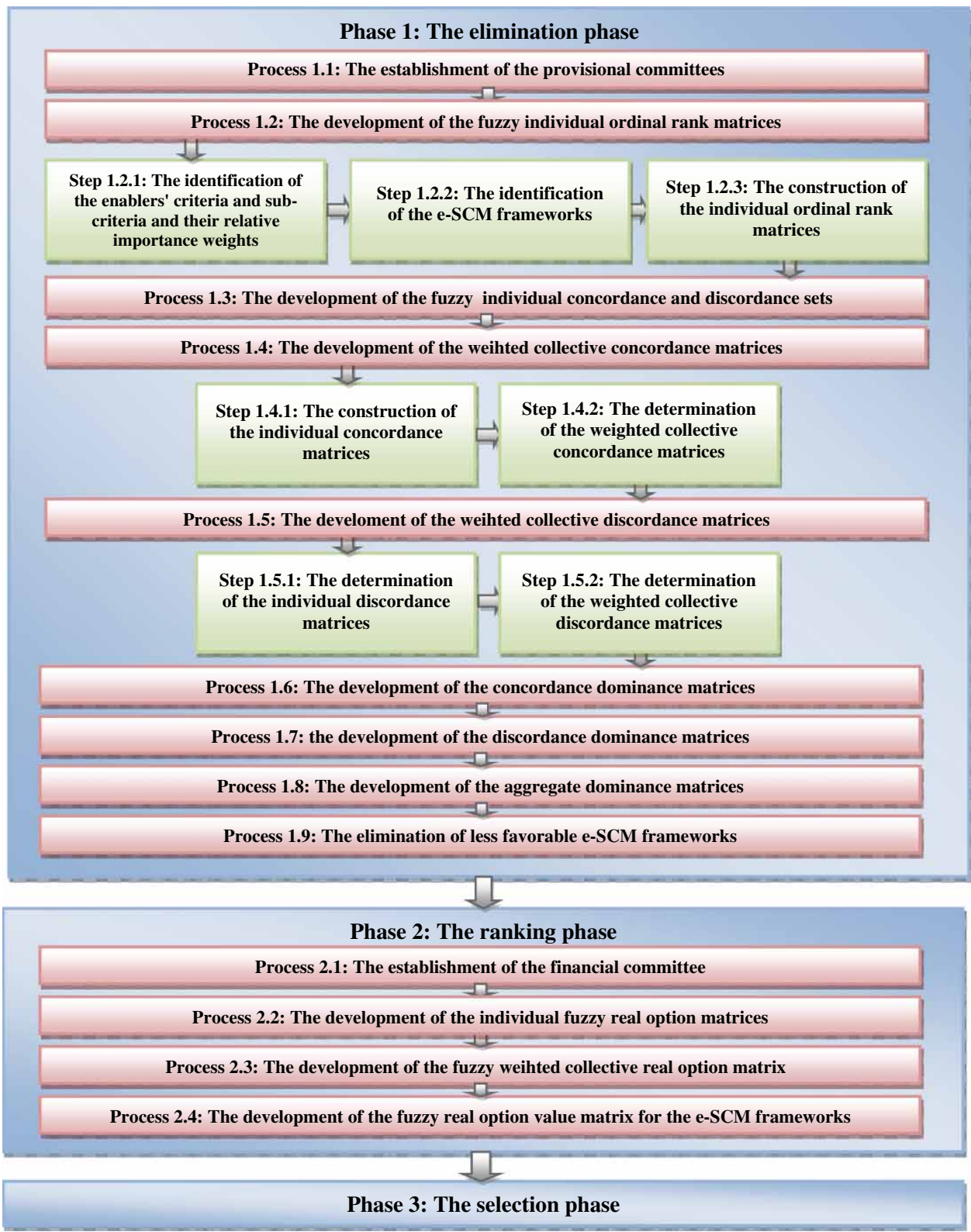

Figure 2. The proposed framework.

for evaluating the financial aspects of the process referred to as the 'financial committee (FC)'. The key duties and responsibilities of the SC include:

(a) obtaining the support of the top management for the overall evaluation process;

(b) overseeing all phases of the evaluation process;

(c) identifying and appointing SC members to serve on different PCs throughout the evaluation process;

(d) coordinating the activities of the PCs and FC during various phases of the evaluation process;

(e) resolving conflicts as they arise; 
(f) selecting the most preferable decision alternative;

(g) developing an action plan for the selected alternative;

(h) obtaining the approval of the top management in the adoption and implementation of the action plan.

The fact that the SC members hold different kinds of knowledge and serve on different PCs makes it more likely that all aspects of the decision will come under consideration. Although the committees must be relatively small (three to five members) to be able to reach consensus, the integration of the Electre method in the proposed framework should reduce the difficulties in seeking compromise or consensus among the committee members (Norese 2006).

\subsection{Phase 1: the elimination phase}

In this phase, we use the fuzzy group Electre method to eliminate the less favourable e-SCM frameworks from the evaluation process. This phase is divided into nine distinct processes. Initially, we establish an SC. Let us assume that the SC members are as follows:

$$
\mathrm{e}-\mathrm{SCMC}=\left(T_{1}(1), T_{1}(2), \ldots, T_{1}(m)\right)
$$

Process 1.1: the establishment of the PCs. In step 1.1, the SC establishes the following $q_{i}$ PCs to determine which frameworks would be eliminated from consideration:

$$
T(i)=\left(T_{1}(i), T_{2}(i), \ldots, T_{q_{i}}(i)\right)
$$

Next, the following voting power weights are assigned to the PC members by the SC:

$$
V(i)=\left[v_{1}(i), v_{2}(i), \ldots, v_{q_{i}}(i)\right]
$$

Several approaches ranging from relatively simple ones, such as point allocation, direct rating, or trade-off analysis, to somewhat more advanced procedures, such as regression estimates, paired comparisons, Delphi, SMART, or SWING methods, could be used to specify the importance weights in MCDA (Kleindorfer et al. 1993, Salo 1995). Although weight elicitation has been an area of concern in MCDA for quite some time, there are still no preferred methods (Riabacke et al. 2009). In this study, we use the AHP to assign a voting power to the members of the PCs. The process, as described in Section 2.1, is simplified by confining the estimates to a series of pairwise comparisons. We aggregate the individual voting power weights into the group weights with the geometric aggregation rule to avoid the controversies associated with rank reversal (Dyer 1990a, 1990b, Harker and Vargas 1990, Saaty 1990b).

The fundamental principle that underlies the use of multiple DMs in our framework is that a set of DMs can provide more information than a single DM. As information is shared, it is anticipated that better information leads to better decisions in group decision-making. Nevertheless, the aggregation of individual judgements into a single group judgement is somewhat challenging. The aggregation procedures in the literature are often categorised into mathematical and behavioural approaches, although in practice aggregation might involve some aspects of both. Mathematical aggregation methods are intended to combine individual judgements into a single 'combined' judgement through aggregation methods such as arithmetic or geometric means. In contrast, behavioural aggregation methods attempt to generate agreement among the DMs through interaction. In this study, we use aggregation methods that involve both mathematical and behavioural approaches throughout the evaluation process. For example, face-to-face interaction is used to generate various alternative frameworks, and the geometric aggregation mean is used to combine individual pairwise comparison judgements from AHP into a group judgement. 
Process 1.2: the development of the fuzzy individual ordinal rank matrices. In this process, we develop the fuzzy individual ordinal rank matrices based on each enabler's criterion. This step is divided into the following three steps.

Step 1.2.1: the identification of the enablers' criteria and subcriteria and their relative importance weights. In this step, the SC identifies the following enablers' criteria and subcriteria: $x_{1}, x_{2}, \ldots, x_{m}$ and $x_{1}(i), x_{2}(i), \ldots, x_{m_{i}}(i)$, respectively. Let us assume that the importance weights of the subcriteria are identified as follows:

$$
w(i)=\left(w_{1}(i), w_{2}(i), \ldots, w_{m_{i}}(i)\right)
$$

Again, we use the AHP to estimate these importance weights and the geometric aggregation rule to aggregate them into group weights.

Step 1.2.2: the identification of the e-SCM frameworks. In this step, the SC identifies the alternative e-SCM frameworks. Let us assume that the SC has identified the following $n$ frameworks:

$$
F=\left[F_{1} F_{2}, \ldots, F_{i}, \ldots, F_{n}\right]
$$

The generation and screening of the alternatives in MCDA require a complete understanding of the problem as well as a great deal of creativity and imagination (Walker 1988). One very useful strategy is to begin the process by screening out those alternatives that do not appear to warrant further attention (Hobbs and Meier 2000). Screening allows the DM to concentrate on a smaller set of alternatives. This is especially useful for pairwise comparison-based methods. As the number of the decision alternatives increases, the number of required pairwise comparisons increases exponentially.

Many approaches have been adapted for screening alternatives. The most widely used method is Pareto-optimality-based screening, an application of the concept of Pareto optimality (Rios Insua and French 1991). Outranking methods such as PROMETHEE (Vincke 1992), linguistic methods such as lexicographic constraints (MacCrimmon 1973), and case-based distance methods (Chen et al. 2008) are also used for screening.

Step 1.2.3: the construction of the individual ordinal rank matrices. With regard to steps 1.2.1 and 1.2.2, each SC member constructs his/her fuzzy individual ordinal rank matrix based on the enabler's criteria as follows:

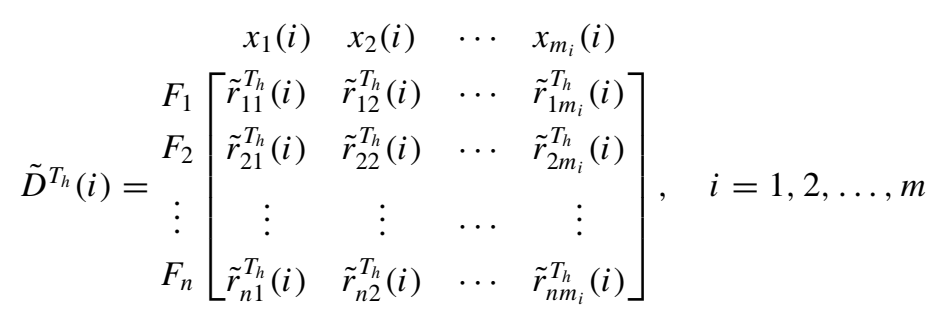

Process 1.3: the development of the fuzzy individual concordance and discordance sets. For each pair of e-SCM frameworks, $k$ and $l(k, l=1,2, \ldots, n$ and $k \neq l)$, the set of subcriteria for each enabler's criterion, $J=\{j \mid j=1,2, \ldots, m\}$, is divided into two distinct subsets. The concordance set $C_{k l}^{T_{h_{i}}}(i)$ of $F_{k}$ and $F_{l}$ is composed of all subcriteria for which the e-SCM framework $F_{k}$ is preferred to e-SCM framework $F_{l}$ :

$$
C_{k l}^{T_{h}}(i)=\left\{j \mid \tilde{r}_{k j}^{T_{h}}(i) \geq \tilde{r}_{l j}^{T_{h}}(i)\right\}
$$

Similarly, the discordance set is defined as follows:

$$
D_{k l}^{T_{h}}(i)=\left\{j \mid \tilde{r}_{k j}^{T_{h}}(i)<\tilde{r}_{l j}^{T_{h}}(i)\right\}
$$


Process 1.4: the development of the weighted collective concordance matrices. In this process, we develop the weighted collective concordance matrices. This process is divided into the following two steps:

Step 1.4.1: the construction of the individual concordance matrices. The relative value of the concordance set is measured by means of the concordance index. The concordance index is equal to the sum of the weights associated with those subcriteria which are contained in the concordance set. Therefore, the individual concordance matrix for the $i$ th enabler's criterion is constructed as follows:

$$
C^{T_{h}}(i)=\left[\begin{array}{cccc}
- & c_{12}^{T_{h}}(i) & \cdots & c_{1 n}^{T_{h}}(i) \\
c_{21}^{T_{h}}(i) & - & \cdots & c_{2 n}^{T_{h}}(i) \\
\vdots & \vdots & \cdots & \vdots \\
c_{n 1}^{T_{h}}(i) & c_{n 2}^{T_{h}}(i) & \cdots & -
\end{array}\right]
$$

where the concordance index $c_{k l}^{T_{h}}(i)$ between the e-SCM framework $F_{k}$ and the e-SCM framework $F_{l}$ is defined as follows:

$$
c_{k l}^{T_{h}}(i)=\sum_{j \in C_{k l}^{T_{h}(i)}} w_{j}(i)
$$

Step 1.4.2: the determination of the weighted collective concordance matrices. In this step, we determine the weighted collective concordance matrix for the $i$ th enabler's criterion as follows:

$$
C(i)=\left[\begin{array}{cccc}
- & c_{12}(i) & \cdots & c_{1 n}(i) \\
c_{21}(i) & - & \cdots & c_{2 n}(i) \\
\vdots & \vdots & \cdots & \vdots \\
c_{n 1}(i) & c_{n 2}(i) & \cdots & -
\end{array}\right]
$$

where

$$
\begin{aligned}
c_{k l}(i) & =\sqrt[s]{\left[c_{k l}^{T_{1}}(i)\right]^{v_{1}(i)} \cdot\left[c_{k l}^{T_{2}}(i)\right]^{v_{2}(i)} \ldots\left[c_{k l}^{T_{q_{i}}}(i)\right]^{v_{q_{i}(i)}}} \\
s & =v_{1}(i)+v_{2}(i)+\cdots+v_{q_{i}}(i)
\end{aligned}
$$

Process 1.5: the development of the weighted collective discordance matrices. In this process, we develop the weighted collective discordance matrices. This process is divided into the following two steps.

Step 1.5.1: the determination of the individual discordance matrices. The concordance index reflects the relative dominance of an e-SCM framework over a competing e-SCM framework on the basis of the relative weight attached to the successive subcriterion. So far, no attention has been paid to the degree to which the performance of an e-SCM framework, $F_{k}$, is worse than the performance of the competing e-SCM framework $F_{l}$. Therefore, a second index, called the discordance index, is determined to capture this information. The individual discordance matrix for the $i$ th enabler's criterion is constructed as follows:

$$
D^{T_{h}}(i)=\left[\begin{array}{cccc}
- & d_{12}^{T_{h}}(i) & \cdots & d_{1 n}^{T_{h}}(i) \\
d_{21}^{T_{h}}(i) & - & \cdots & d_{2 n}^{T_{h}}(i) \\
\vdots & \vdots & \cdots & \vdots \\
d_{n 1}^{T_{h}}(i) & d_{n 2}^{T_{h}}(i) & \cdots & -
\end{array}\right]
$$


where the discordance index is defined as follows:

$$
\begin{aligned}
& d_{k l}^{T_{h}}(i)=\frac{\max _{j \in D_{k l}^{T_{h}}(i)}\left|v_{k j}^{T_{h}}(i)-v_{l j}^{T_{h}}(i)\right|}{\max _{j \in J}\left|v_{k j}^{T_{h}}-v_{l j}^{T_{h}}(i)\right|} \\
& v_{k j}^{T_{h}}(i)=w_{j}(i) \cdot E\left[\tilde{r}_{k j}^{T_{h}}(i)\right]
\end{aligned}
$$

Since $\tilde{r}_{k l}^{T_{h}}(i)$ is a trapezoidal fuzzy number

$$
\tilde{r}_{k j}^{k}(i)=\left(\left(r_{k j}^{T_{h}}(i)\right)^{c},\left(r_{k j}^{T_{h}}(i)\right)^{d},\left(r_{k j}^{T_{h}}(i)\right)^{\alpha},\left(r_{k j}^{T_{h}}(i)\right)^{\beta}\right)
$$

its expected value can be derived as follows:

$$
E\left(\tilde{r}_{k j}^{T_{h}}(i)\right)=\frac{\left(r_{k j}^{T_{h}}(i)\right)^{c}+\left(r_{k j}^{T_{h}}(i)\right)^{d}}{2}+\frac{\left(r_{k j}^{T_{h}}(i)\right)^{\beta}-\left(r_{k j}^{T_{h}}(i)\right)^{\alpha}}{6}
$$

Step 1.5.2: the determination of the weighted collective discordance matrices. In this step, we determine the weighted collective discordance matrix for the $i$ th enabler's criterion as follows:

$$
D(i)=\left[\begin{array}{cccc}
- & d_{12}(i) & \cdots & d_{1 n}(i) \\
d_{21}(i) & - & \cdots & d_{2 n}(i) \\
\vdots & \vdots & \cdots & \vdots \\
d_{n 1}(i) & d_{n 2}(i) & \cdots & -
\end{array}\right]
$$

where

$$
d_{k l}(i)=\sqrt[s]{\left[d_{k l}^{T_{1}}(i)\right]^{v_{1}(i)} \cdot\left[d_{k l}^{T_{2}}(i)\right]^{v_{2}(i)} \cdots\left[d_{k l}^{T_{q_{i}}}(i)\right]^{v_{q_{i}(i)}}}
$$

Process 1.6: the development of the concordance dominance matrices. In this process, we develop the concordance dominance matrices. These matrices are calculated with the aid of a threshold value for the concordance index. The e-SCM framework $F_{k}$ will only have a chance of dominating e-SCM framework $F_{l}$, if its corresponding concordance index $c_{k l}^{T_{h}}(i)$ exceeds at least a certain threshold value $\bar{c}(i)$. Therefore, the concordance dominance matrices are developed based on each enabler's criterion as follows:

$$
F(i)=\left[\begin{array}{cccc}
- & f_{12}(i) & \cdots & f_{1 n}(i) \\
f_{21}(i) & - & \cdots & f_{2 n}(i) \\
\vdots & \vdots & \cdots & \vdots \\
f_{n 1}(i) & f_{n 2}(i) & \cdots & -
\end{array}\right]
$$

where

$$
\begin{aligned}
\bar{c}(i) & =\frac{\sum_{\substack{k=1 \\
k \neq l}}^{n} \sum_{\substack{l=1 \\
l \neq k}}^{n} c_{k l(i)}}{n(n-1)} \\
f_{k l}(i) & =1, \quad \text { if } c_{k l}(i) \geq \bar{c} \\
f_{k l}(i) & =0, \quad \text { if } c_{k l}(i)<\bar{c}
\end{aligned}
$$

Process 1.7: the development of the discordance dominance matrices. In this process, we develop the discordance dominance matrices. These matrices are constructed similar to the concordance 
matrices on the basis of the threshold value $\bar{d}$ to the discordance as follows:

$$
G(i)=\left[\begin{array}{cccc}
- & g_{12}(i) & \cdots & g_{1 n}(i) \\
g_{21}(i) & - & \cdots & g_{2 n}(i) \\
\vdots & \vdots & \cdots & \vdots \\
g_{n 1}(i) & g_{n 2}(i) & \cdots & -
\end{array}\right]
$$

where the elements of $g_{k l}(i)$ in the discordance dominance matrix $G(i)$ are calculated as follows:

$$
\begin{aligned}
& \bar{d}(i)=\frac{\sum_{\substack{k=1 \\
k \neq l}}^{n} \sum_{\substack{l=1 \\
l \neq k}}^{n} d_{k l}(i)}{n(n-1)} \\
& g_{k l}(i)=1, \quad \text { if } d_{k l}(i) \leq \bar{d} \\
& g_{k l}(i)=0, \quad \text { if } d_{k l}(i)>\bar{d}
\end{aligned}
$$

Process 1.8: the development of the aggregate dominance matrices. In this process, we develop the aggregate dominance matrices by identifying the intersection of the concordance dominance matrix $F(i)$ and discordance dominance matrix $G(i)$. The aggregate dominance matrix $E(i)$ is constructed as follows:

$$
E(i)=\left[\begin{array}{cccc}
- & e_{12}(i) & \cdots & e_{1 n}(i) \\
e_{21}(i) & - & \cdots & e_{2 n}(i) \\
\vdots & \vdots & \cdots & \vdots \\
e_{n 1}(i) & e_{n 2}(i) & \cdots & -
\end{array}\right]
$$

where

$$
e_{k l}(i)=f_{k l}(i) \cdot g_{k l}(i)
$$

Process 1.9: the elimination of less favourable e-SCM frameworks. In this process, we eliminate the less favourable e-SCM frameworks. The following collective aggregate dominance matrix $E$ gives the partial preference ordering of the e-SCM frameworks:

$$
E=\left[\begin{array}{cccc}
- & e_{12} & \cdots & e_{1 n} \\
e_{21} & - & \cdots & e_{2 n} \\
\vdots & \vdots & \cdots & \vdots \\
e_{n 1} & e_{n 2} & \cdots & -
\end{array}\right]
$$

where

$$
e_{k l}=e_{k l}(1) \cdot g_{k l}(2) \ldots g_{k l}(m)
$$

The condition that the e-SCM framework $F_{k}$ is not dominated is described as follows:

$$
\begin{aligned}
& e_{k l}=1, \quad \text { for at least one } l, l=1,2, \ldots, m, k \neq l \\
& e_{i k}=0, \quad \text { for all } i, i=1,2, \ldots, m, i \neq k, i \neq l
\end{aligned}
$$

That is, if $e_{k l}=1$, then the e-SCM framework $F_{k}$ is preferred to the e-SCM framework $F_{l}$ for both the concordance and discordance criteria, but the e-SCM framework $F_{k}$ still can be dominated by the other e-SCM frameworks. Consequently, the dominated e-SCM frameworks are identified and eliminated with the fuzzy group Electre method and the non-dominated e-SCM frameworks are moved to Phase 2. 


\subsection{Phase 2: the ranking phase}

In order to ensure the successful implementation of an e-SCM framework, we must select and implement the e-SCM framework that adds the most financial value. We consider the nondominated e-SCM framework selection as a strategic investment decision in deferral times and apply the fuzzy real options approach to rank the non-dominated e-SCM frameworks. This phase is divided into the following four processes.

Process 2.1: the establishment of the FC. In this process, we establish the FC as follows:

$$
T(F)=\left[T_{1}(f), T_{2}(f), \ldots, T_{q_{n}}(f)\right]
$$

Next, the SC assigns a voting power weight to each member of the FC as follows:

$$
V(F)=\left[v_{1}(f), v_{2}(f), \ldots, v_{q_{n}}(f)\right]
$$

Process 2.2: the development of the individual fuzzy real option matrices. In this process, we develop the individual fuzzy real option matrices for the FC members as follows:

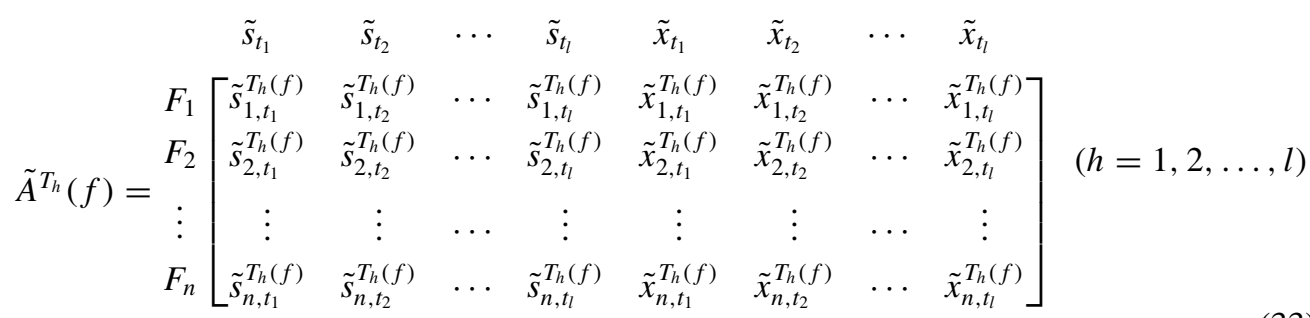

Process 2.3: the development of the fuzzy weighted collective real option matrix. Next, we develop the fuzzy weighted collective real option matrix by aggregating the individual fuzzy real option matrices by their voting powers as follows:

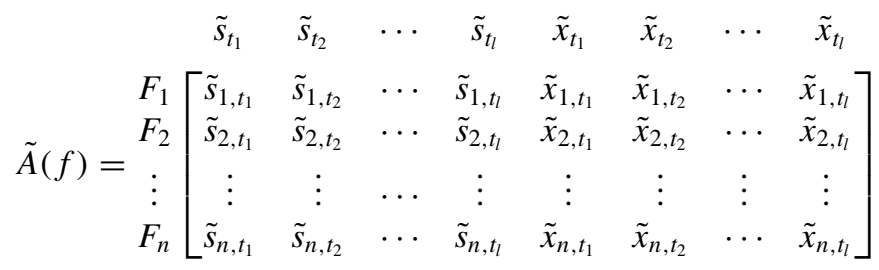

where:

$$
\begin{gathered}
\tilde{s}_{i, t_{j}}=\frac{\sum_{h=1}^{q_{n}}\left(v_{h}(f)\right)\left(\tilde{s}_{i, t_{j}}^{T_{h}(f)}\right)}{\sum_{h=1}^{q_{n}} v_{h}(f)} \quad(i=1,2, \ldots, n \text { and } j=1,2, \ldots, l) \\
\tilde{x}_{i, t_{j}}=\frac{\sum_{h=1}^{q_{n}}\left(v_{h}(f)\right)\left(\tilde{x}_{i, t_{j}}^{T_{h}(f)}\right)}{\sum_{h=1}^{q_{n}} v_{h}(f)} \quad(i=1,2, \ldots, n \text { and } j=1,2, \ldots, l)
\end{gathered}
$$

Process 2.4: the development of the fuzzy real option value matrix for the e-SCM frameworks. In this process, we develop the fuzzy real option value matrix for the non-dominated e-SCM frameworks. The real option value of the non-dominated e-SCM frameworks at times $t_{1}, t_{2}, \ldots, t_{l}$ 
can be determined by the following fuzzy real option value matrix:

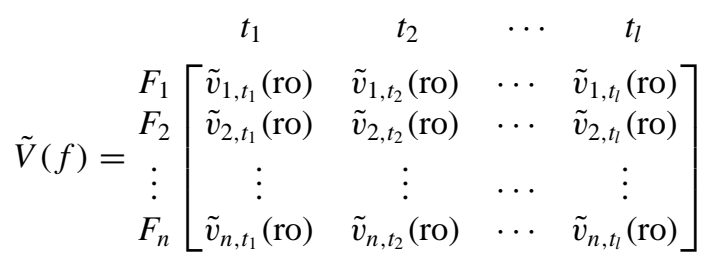

where

$$
\tilde{v}_{i, t_{j}}(\mathrm{ro})=\tilde{s}_{i, t_{j}} \cdot e^{-\delta \cdot t_{j}} \cdot n\left\{d_{11, t_{j}}\right\}-\tilde{x}_{i, t_{j}} \cdot e^{-r \cdot t_{j}} \cdot n\left\{d_{21, t_{j}}\right\}
$$

The e-SCM framework $i$ th cumulative normal probability distributions for $d_{1}$ and $d_{2}$ are as follows:

$$
\begin{aligned}
& n\left\{d_{1, t_{1}}\right\} \quad n\left\{d_{1, t_{2}}\right\} \quad \cdots \quad n\left\{d_{1, t_{l}}\right\} \quad n\left\{d_{2, t_{1}}\right\} \quad n\left\{d_{2, t_{2}}\right\} \quad \cdots \quad n\left\{d_{2, t_{l}}\right\} \\
& N(f)=\begin{array}{c}
F_{1} \\
F_{2} \\
\vdots \\
F_{n}
\end{array}\left[\begin{array}{cccccccc}
n\left\{d_{11, t_{1}}\right\} & n\left\{d_{11, t_{2}}\right\} & \cdots & n\left\{d_{11, t_{l}}\right\} & n\left\{d_{21, t_{1}}\right\} & n\left\{d_{21, t_{2}}\right\} & \cdots & n\left\{d_{21, t_{l}}\right\} \\
n\left\{d_{12, t_{1}}\right\} & n\left\{d_{12, t_{2}}\right\} & \cdots & n\left\{d_{12, t_{l}}\right\} & n\left\{d_{22, t_{1}}\right\} & n\left\{d_{22, t_{2}}\right\} & \cdots & n\left\{d_{22, t_{l}}\right\} \\
\vdots & \vdots & \cdots & \vdots & \vdots & \vdots & \cdots & \vdots \\
n\left\{d_{1 n, t_{1}}\right\} & n\left\{d_{1 n, t_{2}}\right\} & \cdots & n\left\{d_{1 n, t_{l}}\right\} & n\left\{d_{2 n, t_{1}}\right\} & n\left\{d_{2 n, t_{2}}\right\} & \cdots & n\left\{d_{2 n, t_{l}}\right\}
\end{array}\right]
\end{aligned}
$$

where

$$
\begin{aligned}
d_{1 i, t_{j}} & =\frac{\ln \left(E\left(\tilde{s}_{i, t_{j}}\right) /\left(\tilde{x}_{i, t_{j}}\right)\right)+t_{j} \cdot\left(r_{i}-\delta_{i}+\sigma_{i, t_{j}}^{2} / 2\right)}{\sigma_{i, t_{j}} \cdot \sqrt{t_{j}}} \\
d_{2 i, t_{j}} & =\frac{\ln \left(E\left(\tilde{s}_{i, t_{j}}\right) /\left(\tilde{x}_{i, t_{j}}\right)\right)+t_{j} \cdot\left(r_{i}-\delta_{i}-\sigma_{i, t_{j}}^{2} / 2\right)}{\sigma_{i, t_{j}} \cdot \sqrt{t_{j}}}
\end{aligned}
$$

where the following trapezoidal fuzzy numbers can be used for the individual fuzzy present values of the expected payoffs and costs of the $i$ th non-dominated e-SCM framework at the time $t_{j}$ by the FC member $T_{h}(f)$ :

$$
\begin{aligned}
\tilde{s}_{i, t_{j}}^{T(f)} & =\left(\left(s_{i, t_{j}}^{T(f)}\right)^{c},\left(s_{i, t_{j}}^{T(f)}\right)^{d},\left(s_{i, t_{j}}^{T(f)}\right)^{\alpha},\left(s_{i, t_{j}}^{T(f)}\right)^{\beta}\right) \\
\tilde{x}_{i, t_{j}}^{T} & =\left(\left(x_{i, t_{j}}^{T(f)}\right)^{c},\left(x_{i, t_{j}}^{T(f)}\right)^{d},\left(x_{i, t_{j}}^{T(f)}\right)^{\alpha},\left(x_{i, t_{j}}^{T(f)}\right)^{\beta}\right), \quad i=1,2, \ldots, n, j=1,2, \ldots, l
\end{aligned}
$$

Next, we use the approach proposed by Carlsson et al. (2007) to determine the expected value and the variance of the non-dominated e-SCM frameworks as follows:

$$
\begin{aligned}
E\left(\tilde{s}_{i, t_{j}}\right) & =\frac{\left(s_{i, t_{j}}\right)^{c}+\left(s_{i, t_{j}}\right)^{d}}{2}+\frac{\left(s_{i, t_{j}}\right)^{\beta}-\left(s_{i, t_{j}}\right)^{\alpha}}{6} \\
E\left(\tilde{x}_{i, t_{j}}\right) & =\frac{\left(x_{i, t_{j}}\right)^{c}+\left(x_{i, t_{j}}\right)^{\alpha}}{2}+\frac{\left(x_{i, t_{j}}\right)^{\gamma}-\left(x_{i, t_{j}}\right)^{\beta}}{6} \\
\sigma_{i, t_{j}}^{2} & =\frac{\left(\left(s_{i, t_{j}}\right)^{d}-\left(s_{i, t_{j}}\right)^{c}\right)^{2}}{4}+\frac{\left(\left(s_{i, t_{j}}\right)^{d}-\left(s_{i, t_{j}}\right)^{c}\right)\left(\left(s_{i, t_{j}}\right)^{\alpha}+\left(s_{i, t_{j}}\right)^{\beta}\right)}{6}+\frac{\left(\left(s_{i, t_{j}}\right)^{\alpha}+\left(s_{i, t_{j}}\right)^{\beta}\right)^{2}}{24}
\end{aligned}
$$




\subsection{Phase 3: the selection phase}

In this phase, we select the excellent e-SCM framework by considering the rankings obtained in Phase 2 as the coefficients of the objective function in the following mathematical model with regard to a series of applicable e-business and e-SCM constraints:

$$
\begin{aligned}
\operatorname{Max} Z_{f}= & \frac{E\left[\tilde{v}_{1, t_{1}}(\text { ro })\right]}{E\left[\tilde{v}_{1, t_{1}}(\text { ro })\right]+\cdots+E\left[\tilde{v}_{n, t_{1}}(\text { ro })\right]} \cdot Z_{1}^{t_{1}}+\cdots \\
& +\frac{E\left[\tilde{v}_{1, t_{l}}(\text { ro })\right]}{E\left[\tilde{v}_{1, t_{l}}(\text { ro })\right]+\cdots+E\left[\tilde{v}_{n, t_{l}}(\text { ro })\right]} \cdot Z_{n}^{t_{l}} \quad(\text { Model P) }
\end{aligned}
$$

Subject to:

$$
\begin{aligned}
& f\left(z_{1}^{t_{1}}, z_{1}^{t_{2}} \ldots, z_{n}^{t_{l}}\right) \leq 0 \\
& z_{1}^{t_{1}}+z_{1}^{t_{2}}+\cdots+z_{n}^{t_{l}} \leq 1 \\
& z_{i}^{t_{j}}=0,1, \quad(i=1,2, \ldots, n ; j=1,2, \ldots, l)
\end{aligned}
$$

where $f\left(z_{1}^{t_{1}}, z_{1}^{t_{2}} \ldots, z_{n}^{t_{l}}\right)$ is a given function of the $n$ non-dominated e-SCM frameworks. The optimal solution for Model $P$ is the excellent e-SCM framework at time $t_{j}$. In the next section, we present a numerical example to demonstrate the applicability of the proposed model and exhibit the efficacy of the procedures and algorithms.

\section{Case study}

General Turbines $(\mathrm{GT})^{1}$ is a manufacturer of quality wind turbines in Poitiers, France. The company manufactures products which deliver clean renewable energy in a variety of wind conditions and over complex terrains. Company management recognised that there was an urgency to implement a new e-SCM framework as early as possible because of continuous pressure from its customers and suppliers. The proposed framework detailed earlier was used at GT to select an e-SCM framework. To select the e-SCM framework and to participate in the selection process, nine individuals were appointed to the SC by the senior management:

1. capital budgeting manager,

2. e-business process manager,

3. e-customer relations manager,

4. e-marketing manager,

5. e-quality manager,

6. e-supply chain manager,

7. information technology manager,

8. research and development manager,

9. technical support manager.

\subsection{Phase 1: the elimination phase}

In step 1.1, the SC established the following five PCs to determine which frameworks would be eliminated from consideration:

$\mathrm{T}(1)=\left(T_{1}(1), T_{2}(1), T_{3_{i}}(1)\right)$ : comprised of the e-supply chain manager, e-customer relations manager, and e-marketing manager. 
$T(2)=\left(T_{1}(2), T_{2}(2), T_{3_{i}}(2)\right)$ : comprised of the information technology manager, technical support manager, and e-business process manager.

$T(3)=\left(T_{1}(3), T_{2}(3), T_{3_{i}}(3)\right)$ : comprised of the research and development manager, e-business process manager, and information technology manager.

$T(4)=\left(T_{1}(4), T_{2}(4), T_{3_{i}}(4), T_{4}(4)\right)$ : comprised of the e-customer relations manager, e-marketing manager, e-business process manager, and e-supply chain manager.

$T(5)=\left(T_{1}(5), T_{2}(5), T_{3_{i}}(5)\right)$ : comprised of the capital budgeting manager, e-quality manager, and technical support manager.

Next, the SC members individually used Expert Choice software to compute a voting power weight for each PC member on the five PCs. Expert Choice is an AHP-based tool designed for the analysis, synthesis, and validation of complex judgements. The measure of inconsistency provided by AHP and Expert Choice allowed for the examination of inconsistent judgements. The geometric aggregation rule was used to aggregate the individual voting power weights into group voting power weights given below:

$$
\begin{aligned}
& V(1)=(0.4,0.3,0.3) \\
& V(2)=(0.3,0.35,0.35) \\
& V(3)=(0.5,0.25,0.25) \\
& V(4)=(0.4,0.25,0.15,0.20) \\
& V(5)=(0.4,0.2,0.3)
\end{aligned}
$$

In step 1.2.1, the SC used the EFQM model described earlier as a blueprint and developed an excellence model for GT as suggested by the NCVO. The GT excellence model included the following five enablers: (1) strategic e-partnerships; (2) critical e-processes; (3) software; (4) people; and (5) infrastructure. Each enabler (criteria) was further broken down into additional subcriteria. Table 1 presents a listing of the criteria and subcriteria identified by the SC. Each subcriterion is also cross-referenced with one or more relevant references in the literature.

In step 1.2.2, the SC selected the following 12 e-SCM frameworks for possible consideration and adaptation:

- Giménez and Lourenço (2008) [framework A],

- Gunasekaran and Ngai (2004a) [framework B],

- Ke et al. (2009) [framework C],

- Keskinocak et al. (2001) [framework D],

- Lo et al. (2008) [framework E],

- Lu and Wang (2008) [framework F],

- Mukhtar et al. (2009) [framework G],

- Nguyen and Harrison (2004) [framework H],

- Williams et al. (2002) [framework I],

- Wu and Chuang (2009) [framework J],

- Yen et al. (2004) [framework K],

- Yin et al. (2007) [framework L].

The SC conducted several sessions to screen out those frameworks that did not appear to warrant further attention. The SC decided to adopt the following strategy to discard frameworks: if all subcriteria could not be used to measure the performance of a framework, that framework would be discarded. Following this rule, the SC developed Table 2 showing the relationships between the 21 subcriteria and the 12 frameworks under consideration. 
Table 1. The GT's excellence model criteria and subcriteria.

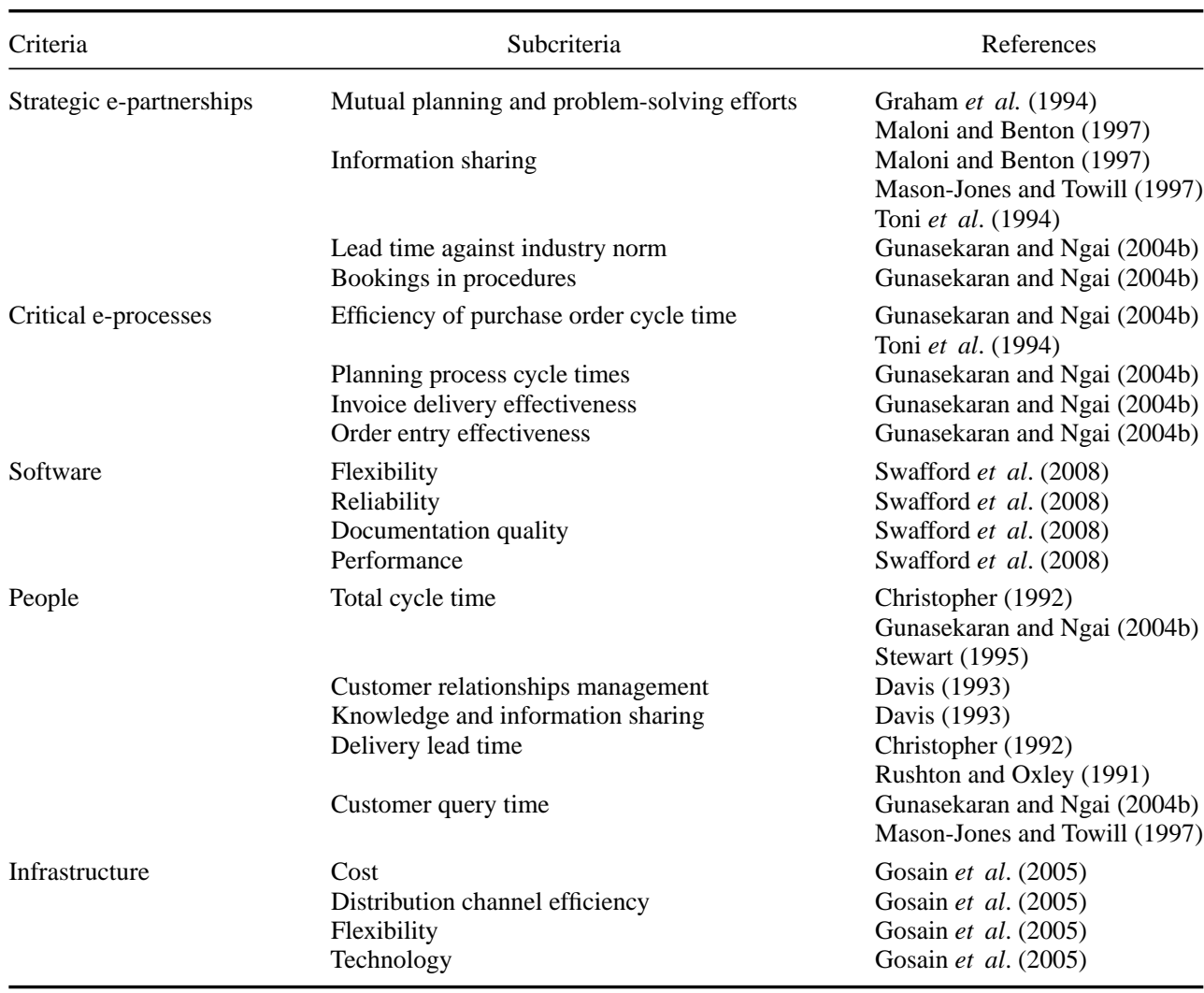

As shown in Table 2, only three frameworks were completely affected by our long list of 21 subcriteria. Nine frameworks were eliminated from further consideration, and the following three frameworks were kept for further consideration:

- Lo et al. (2008) [framework E],

- Lu and Wang (2008) [framework F],

- Yen et al. (2004) [framework K].

Next, the SC members individually computed an importance weight for each subcriterion. The Expert Choice software was used to determine the importance weights. The individual preferences were combined into group preferences given below with the geometric aggregation rule:

$$
\begin{aligned}
& w(1)=(0.3,0.3,0.25,0.15) \\
& w(2)=(0.2,0.3,0.25,0.25) \\
& w(3)=(0.3,0.2,0.2,0.3) \\
& w(4)=(0.35,0.2,0.15,0.15,0.15) \\
& w(5)=(0.4,0.25,0.2,0.15)
\end{aligned}
$$

In step 1.2.3, the PC members constructed their fuzzy individual ordinal rank matrices based on each enabler's criterion. Table 3 presents the fuzzy individual ordinal rank matrices for the GT's excellence model subcriteria.

For example, as shown in Figures 3 and 4, the PC member $T_{1}(1)$ assigned the trapezoidal fuzzy numbers $(0.5,1.5,0.5,0.5)$ and $(1.5,2.5,0.5,0.5)$ to $\tilde{r}_{11}^{T_{1}}(1)$ and $\tilde{r}_{31}^{T_{1}}(1)$ in Table 3 , respectively. 
Table 2. The framework-criteria relationship chart.

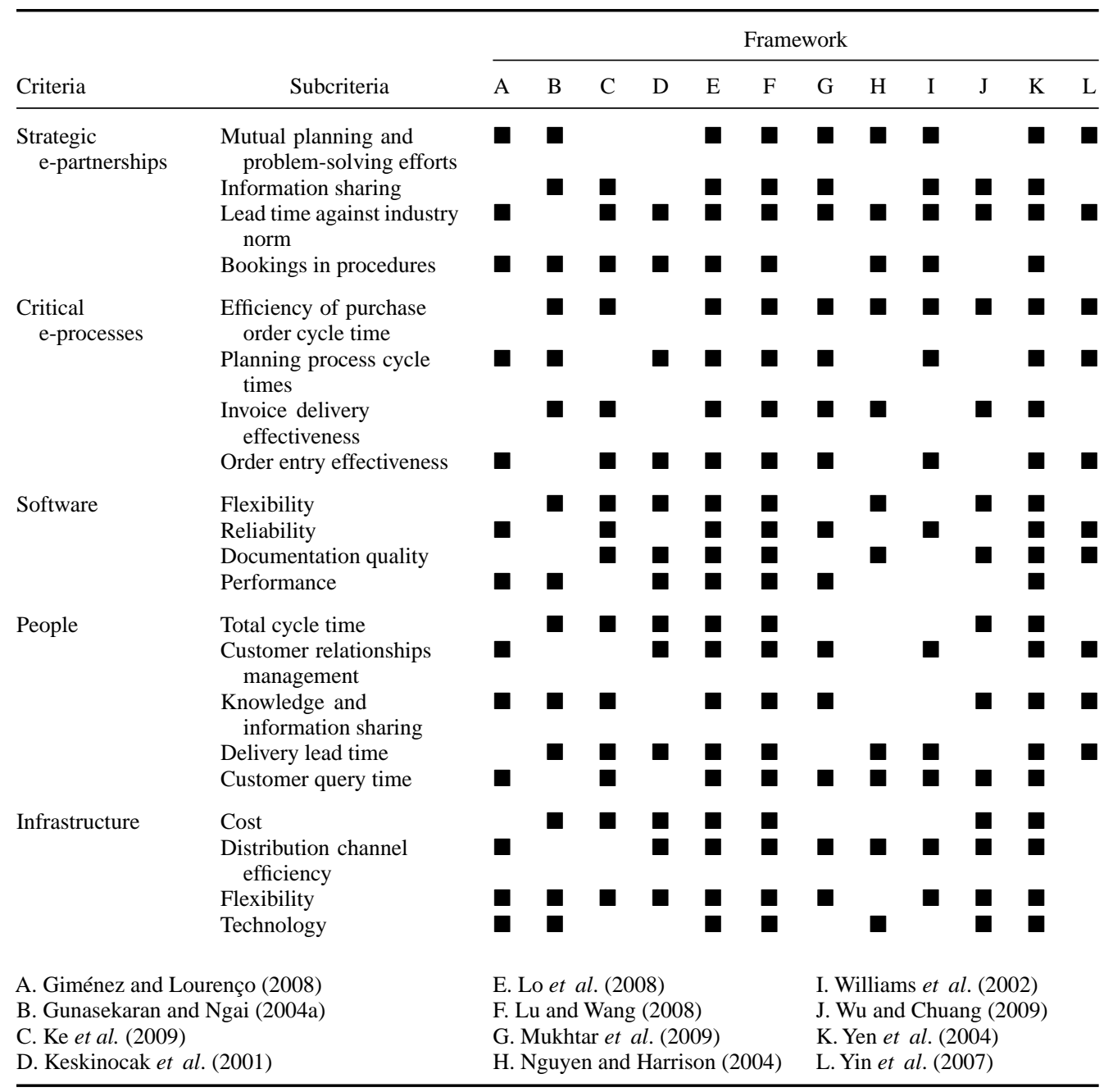

In Process 1.3, Equations (7) and (8) were used to construct the fuzzy individual concordance and discordance sets. For example, as shown in Figure 5, the comparison of two trapezoidal fuzzy numbers $\tilde{r}_{11}^{T_{1}}(1)$ and $\tilde{r}_{31}^{T_{1}}(1)$ results in $\tilde{r}_{11}^{T_{1}}(1) \leq \tilde{r}_{31}^{T_{1}}(1)$. Therefore, in Process 1.4 , based on the criterion of the strategic e-partnerships and the subcriterion of mutual planning and problemsolving efforts, the e-SCM framework K was preferred to e-SCM framework E.

Next, we used Equations (26) and (27) in Process 1.8 to determine the aggregate dominance matrices. Table 4 presents the aggregate dominance matrices for the GT's excellence model subcriteria.

In Process 1.9, we used Equations (28) and (29) to calculate the collective aggregate dominance matrix presented in Table 5 .

As shown in Table 5, the e-SCM framework F was dominated by frameworks E and $\mathrm{K}$ and consequently was eliminated according to the Electre method. However, the preference relations among the non-dominated frameworks were not apparent. In Phase 2, we further analyse frameworks $\mathrm{E}$ and $\mathrm{K}$ and determine the preference relations among them. 
Table 3. The fuzzy individual ordinal rank matrices for the GT's excellence model subcriteria.

\begin{tabular}{|c|c|c|c|c|}
\hline \multirow[b]{2}{*}{ Criteria } & \multirow[b]{2}{*}{ Subcriteria } & \multicolumn{3}{|c|}{ Framework } \\
\hline & & $\mathrm{E}$ & $\mathrm{F}$ & $\mathrm{K}$ \\
\hline \multirow[t]{4}{*}{ Strategic e-partnerships } & $\begin{array}{l}\text { Mutual planning and problem- } \\
\text { solving efforts }\end{array}$ & $(0.5,1.5,0.5,0.5)$ & $(2.5,3.5,0.5,0.5)$ & $(1.5,2.5,0.5,0.5)$ \\
\hline & Information sharing & $(2.5,3.5,0.5,0.5)$ & $(1.5,2.5,0.5,0.5)$ & $(0.5,1.5,0.5,0.5)$ \\
\hline & $\begin{array}{l}\text { Lead time against industry } \\
\text { norm }\end{array}$ & $(0.5,1.5,0.5,0.5)$ & $(2.5,3.5,0.5,0.5)$ & $(1.5,2.5,0.5,0.5)$ \\
\hline & Bookings in procedures & $(0.5,1.5,0.5,0.5)$ & $(1.5,2.5,0.5,0.5)$ & $(2.5,3.5,0.5,0.5)$ \\
\hline \multirow[t]{4}{*}{ Critical e-processes } & $\begin{array}{l}\text { Efficiency of purchase order } \\
\text { cycle time }\end{array}$ & $(0.5,1.5,0.5,0.5)$ & $(1.5,2.5,0.5,0.5)$ & $(2.5,3.5,0.5,0.5)$ \\
\hline & Planning process cycle times & $(0.5,1.5,0.5,0.5)$ & $(2.5,3.5,0.5,0.5)$ & $(1.5,2.5,0.5,0.5)$ \\
\hline & Invoice delivery effectiveness & $(0.5,1.5,0.5,0.5)$ & $(2.5,3.5,0.5,0.5)$ & $(1.5,2.5,0.5,0.5)$ \\
\hline & Order entry effectiveness & $(0.5,1.5,0.5,0.5)$ & $(2.5,3.5,0.5,0.5)$ & $(1.5,2.5,0.5,0.5)$ \\
\hline \multirow[t]{4}{*}{ Software } & Flexibility & $(1.5,2.5,0.5,0.5)$ & $(2.5,3.5,0.5,0.5)$ & $(0.5,1.5,0.5,0.5)$ \\
\hline & Reliability & $(1.5,2.5,0.5,0.5)$ & $(2.5,3.5,0.5,0.5)$ & $(0.5,1.5,0.5,0.5)$ \\
\hline & Documentation quality & $(0.5,1.5,0.5,0.5)$ & $(2.5,3.5,0.5,0.5)$ & $(1.5,2.5,0.5,0.5)$ \\
\hline & Performance & $(0.5,1.5,0.5,0.5)$ & $(2.5,3.5,0.5,0.5)$ & $(1.5,2.5,0.5,0.5)$ \\
\hline \multirow[t]{5}{*}{ People } & Total cycle time & $(1.5,2.5,0.5,0.5)$ & $(2.5,3.5,0.5,0.5)$ & $(0.5,1.5,0.5,0.5)$ \\
\hline & $\begin{array}{l}\text { Customer relationships } \\
\text { management }\end{array}$ & $(1.5,2.5,0.5,0.5)$ & $(2.5,3.5,0.5,0.5)$ & $(0.5,1.5,0.5,0.5)$ \\
\hline & $\begin{array}{l}\text { Knowledge and information } \\
\text { sharing }\end{array}$ & $(0.5,1.5,0.5,0.5)$ & $(2.5,3.5,0.5,0.5)$ & $(1.5,2.5,0.5,0.5)$ \\
\hline & Delivery lead time & $(1.5,2.5,0.5,0.5)$ & $(2.5,3.5,0.5,0.5)$ & $(0.5,1.5,0.5,0.5)$ \\
\hline & Customer query time & $(0.5,1.5,0.5,0.5)$ & $(2.5,3.5,0.5,0.5)$ & $(1.5,2.5,0.5,0.5)$ \\
\hline \multirow[t]{4}{*}{ Infrastructure } & Cost & $(0.5,1.5,0.5,0.5)$ & $(2.5,3.5,0.5,0.5)$ & $(1.5,2.5,0.5,0.5)$ \\
\hline & Distribution channel efficiency & $(0.5,1.5,0.5,0.5)$ & $(2.5,3.5,0.5,0.5)$ & $(1.5,2.5,0.5,0.5)$ \\
\hline & Flexibility & $(0.5,1.5,0.5,0.5)$ & $(1.5,2.5,0.5,0.5)$ & $(2.5,3.5,0.5,0.5)$ \\
\hline & Technology & $(0.5,1.5,0.5,0.5)$ & $(2.5,3.5,0.5,0.5)$ & $(1.5,2.5,0.5,0.5)$ \\
\hline
\end{tabular}

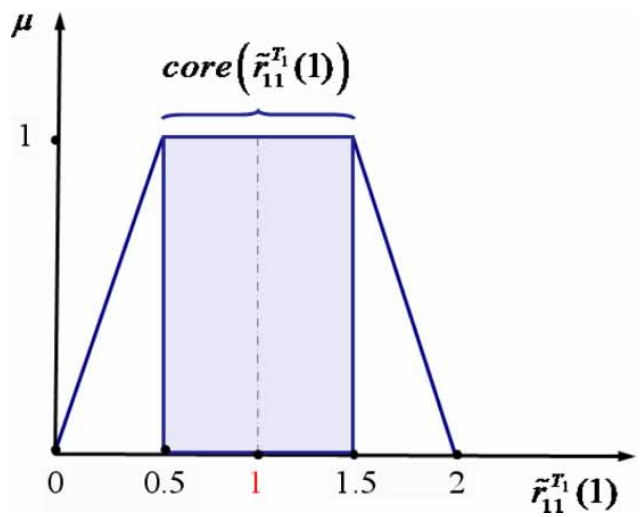

Figure 3. The trapezoidal fuzzy number $\tilde{r}_{11}^{T_{1}}(1)$ applied by $T_{1}(1)$.

\subsection{Phase 2: the ranking phase}

In step 2.1, the FC was instituted as follows:

$T(F)=\left[T_{1}(f), T_{2}(f), T_{3}(f)\right]:$ comprised of the capital budgeting manager, e-quality manger, and e-supply chain manager. 


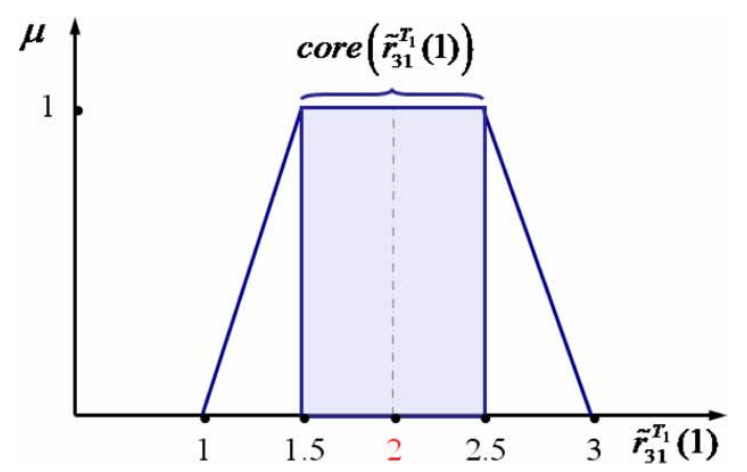

Figure 4. The trapezoidal fuzzy number $\tilde{r}_{31}^{T_{1}}(1)$ applied by $T_{1}(1)$.

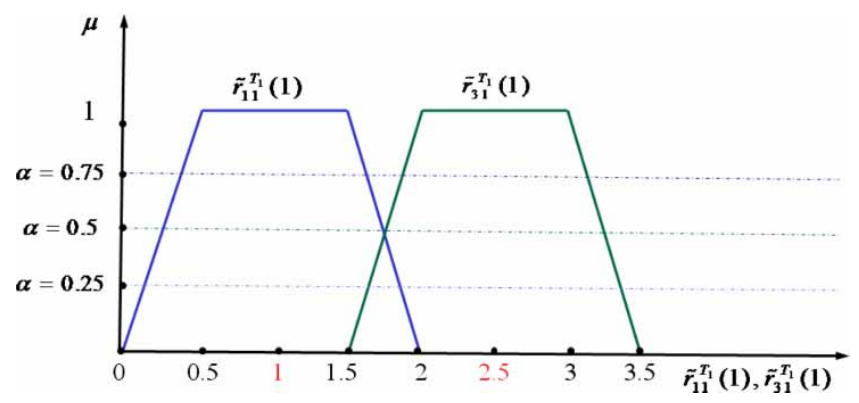

Figure 5. Ranking two trapezoidal fuzzy numbers $\tilde{r}_{11}^{T_{1}}(1)$ and $\tilde{r}_{31}^{T_{1}}(1)$ by the Mabuchi method.

Table 4. The aggregate dominance matrices for the GT's excellence model subcriteria.

\begin{tabular}{lcccc}
\hline \multirow{2}{*}{ Subcriteria } & & \multicolumn{3}{c}{ Framework } \\
\cline { 3 - 5 } Strategic e-partnerships & Framework & E & F & K \\
& 2 & - & 1 & 0 \\
Critical e-processes & 3 & 0 & - & 0 \\
& 1 & 0 & 1 & - \\
Software & 2 & - & 1 & 1 \\
& 3 & 0 & - & 0 \\
People & 1 & 0 & 1 & - \\
& 2 & - & 1 & 0 \\
Infrastructure & 3 & 0 & - & 0 \\
& 1 & - & 1 & - \\
& 2 & 0 & - & 0 \\
& 3 & 1 & 1 & - \\
& 1 & - & 1 & 1 \\
& 2 & 0 & - & 0 \\
& 3 & 0 & 1 & - \\
\hline
\end{tabular}

Table 5. The collective aggregate dominance matrix.

\begin{tabular}{lccc}
\hline & \multicolumn{3}{c}{ e-SCM framework } \\
\cline { 2 - 4 } e-SCM framework & E & F & K \\
\hline 1 & - & 1 & 0 \\
2 & 0 & - & 0 \\
3 & 0 & 1 & - \\
\hline
\end{tabular}


Table 6. The normalised real option values of the non-dominated e-SCM frameworks E and K.

\begin{tabular}{llc}
\hline & \multicolumn{2}{c}{ e-SCM framework } \\
\cline { 2 - 3 } Deferral time & $\mathrm{E}$ & $\mathrm{K}$ \\
\hline 0 & 0.30 & 0.19 \\
1 & 0.45 & 0.18 \\
2 & 0.15 & 0.63 \\
\hline
\end{tabular}

Next, the SC developed the following voting power weights for the three FC members:

$$
V(F)=[0.45,0.25,0.35]
$$

We then used Equations (31)-(43) to determine the normalised real option values of the nondominated e-SCM frameworks E and K for years 0, 1, and 2. As shown in Table 6, the e-SCM framework $\mathrm{E}$ has the best normalised real option value in year 1.

\subsection{Phase 3: the selection phase}

In Phase 3, we considered additional business constraints and utilised the following mathematical model to select the optimal e-SCM framework based on the rankings obtained in Phase 2:

$$
\begin{aligned}
\operatorname{Max} Z_{f}= & 0.30 z_{1}^{0}+0.45 z_{1}^{1}+0.15 z_{1}^{2}+0.19 z_{3}^{0}+0.18 z_{3}^{1}+0.63 z_{3}^{2} \\
\text { Subjectto : } \quad(\text { Model } P) & \\
& z_{1}^{0}+z_{3}^{0}+z_{1}^{1}+z_{3}^{1}+z_{1}^{2}+z_{3}^{2} \leq 1 \\
& z_{1}^{1}+z_{3}^{1} \leq z_{1}^{0}+z_{3}^{0} \\
& z_{1}^{2}+z_{3}^{2} \leq z_{1}^{1}+z_{3}^{1} \\
& 0.30 z_{1}^{0}+0.45 z_{1}^{1}+0.15 z_{1}^{2}+0.19 z_{3}^{0}+0.18 z_{3}^{1}+0.63 z_{3}^{2} \geq 0.3 \\
& z_{1}^{0}, z_{1}^{1}, z_{1}^{2}, z_{3}^{0}, z_{3}^{1}, z_{3}^{2}=0,1
\end{aligned}
$$

According to the optimal solution obtained from Model $P$, the SC selected e-SCM framework E for adoption in year 0 .

It is hard to say for sure which e-SCM framework is the best, but we can make the selection process more comprehensive and systematic. The fuzzy group AHP-Electre method used at GT was intended to enhance decision-making. The nine SC members were highly educated; six of them held graduate degrees in economics and engineering and three of them held undergraduate degrees in business and engineering. To this end, a more logical and persuasive multi-criteria framework was necessary to gain their confidence and support. Although the SC members were educated and creative, their managerial judgement and intuition were limited by their background and experience. Nevertheless, all nine SC members were experienced managers with 7-22 years of tenure in supply chain and logistics management. Upon completion of the e-SCM selection process, the SC met to discuss the results and finalise its recommendations. The nine SC members unanimously agreed that the proposed framework provided invaluable analysis aids and information processing support. They were convinced that the results were unbiased and consistent with their goals and objectives.

Armed with this feedback, the SC members were confident that they could sell their recommendation to the top management. They developed an action plan and agreed to target various 
stakeholders and key people in order to gain their support. They were adamant about the importance of gaining support from the stakeholders before going to the top management for their approval. They began building internal alliances by fostering collaboration and avoiding alienation of potential allies. They discussed the tangible and intangible benefits of the selected e-SCM framework with the key people who in turn agreed to support the proposed recommendation. The $\mathrm{SC}$ presented its recommendation to the top management who in turn approved the proposed eSCM framework. The top management also charged the SC with the development of a long-term plan to measure the success of the proposed framework.

\section{Conclusions and future research directions}

We recognise that the rapid growth of the Internet and electronic commerce has opened new avenues for companies to distribute goods and collaborate with their suppliers and customers. E-procurement, e-tailing, and e-marketplaces are but a few examples of Internet-abled business applications that have revolutionised certain processes in supply chains and have given rise to e-SCM. Given that pace of change, we have demonstrated a real-world application of a model that will allow for enhanced communication in the supply chain, thereby increasing information flow and creating other efficiencies for the firm. The modelling process used allowed for an integrated Electre approach within the framework of the EFQM, fuzzy logic, ROA, and optimisation techniques. This integrative approach allowed, as well, for the melding of both qualitative and quantitative data in a process that created an opportunity for DMs to make better and more informed decisions regarding the selection of an e-SCM framework. We also demonstrated that our methodology delivers results when ambiguity exists due to realistic assumptions of vagueness in the decision-making process.

The contribution of the proposed method is fourfold: (1) it addresses the gaps in the SCM literature on the effective and efficient assessment of the e-SCM frameworks; (2) it is grounded in the excellence model introduced by the EFQM; (3) it provides a comprehensive and systematic framework that combines ROA with a group Electre method; and (4) it considers fuzzy logic and fuzzy sets to represent ambiguous, uncertain, or imprecise information. We used a real-world case study to demonstrate the applicability of the proposed framework and exhibit the efficacy of the procedures and algorithms. The analysis of this case study allows for the articulation of a series of key factors that can be considered important in contributing to the successful implementation of the e-SCM framework. The first element is getting the key people on board. The second factor is building internal alliances. The third key ingredient is the persistent and systematic process in place to evaluate the e-SCM success.

We stress that our contribution addresses yet a small part of the issues that are involved with e-SCM framework evaluation and selection. It is safe to say that e-SCM assessment as a discipline is in its infancy. Therefore, we hope that the study presented here can inspire others to pursue further research in this area. Only through additional application can refinements in the understanding of how to better the process of making decisions in an uncertain environment occur.

\section{References}

Bailey, D., Goonetilleke, A., and Campbell, D., 2003. A new fuzzy multicriteria evaluation method for group site selection in GIS. Journal of Multicriteria Decision Analysis, 12 (6), 337-347.

Belacel, N., 2000. Multicriteria assignment method PROAFTN: methodology and medical applications. European Journal of Operational Research, 125 (1), 175-183.

Belacel, N., Ravala, H.B., and Punnenc, A.P., 2007. Learning multicriteria fuzzy classification method PROAFTN from data. Computers and Operations Research, 34 (7), 1885-1898.

Bellman, R. and Zadeh, L.A., 1970. Decision making in a fuzzy environment. Management Science, 17B (4), $141-164$. 
Belton, V. and Stewart, T.J., 2002. Multiple criteria decision analysis: an integrated approach. Norwell, MA: Kluwer.

Black, F. and Scholes, M., 1973. The pricing of options and corporate liabilities. The Journal of Political Economy, $81(3), 637-654$

Cagliano, R., Caniato, F., and Spina, G., 2005. E-business strategy: how companies are shaping their supply chain through the Internet. International Journal of Operations and Production Management, 23 (1), 1142-1162.

Carlsson, C. and Fullér, R., 2003. A fuzzy approach to real option valuation. Fuzzy Sets and Systems, 139 (2), $297-312$.

Carlsson, C., et al., 2007. A fuzzy approach to R\&D project portfolio selection. International Journal of Approximate Reasoning, 44 (2), 93-105.

Chen, C.T., 2000. Extensions of the TOPSIS for group decision-making under fuzzy environment. Fuzzy Sets and Systems, 114 (1), 1-9.

Chen, L., Long, J., and Yan, T., 2004. E-supply chain implementation strategies in a transitional economy. International Journal of Information Technology and Decision Making, 3 (2), 563-574.

Chen, T., et al., 2007. Fuzzy real option analysis for IT investment in nuclear power station. Computational science ICCS 2007, 27-30 May 2007, Beijing, China, Berlin: Springer, 953-959.

Chen, Y., Kilgour, D.M., and Hipel, K.W., 2008. A case-based distance model for screening in multiple criteria decision aid. $O M E G A, 36(3), 373-383$.

Chopra, S. and van Mieghem, J.A., 2000. Which e-business is right for your supply chain? Supply Chain Management Review, 4 (3), 32-40.

Chorafas, D.N., 2001. Integrating ERP, CRM, supply chain management, and smart materials. Boca Raton, FL: Auerbach.

Christopher, M., 1992. Logistics and supply chain management. London: Pitman Publishing.

Chrysafis, K.A. and Papadopoulos, B.K., 2009. On theoretical pricing of options with fuzzy estimators. Journal of Computational and Applied Mathematics, 223 (2), 552-566.

Collan, M., Fullér, R., and Mezei, J., 2009. A fuzzy pay-off method for real option valuation. Journal of Applied Mathematics and Decision Sciences, [online], 2009. Available from http://www.hindawi.com/journal/ads/2009/238196.html.

Costa, J.P., et al., 2003. The AGAP system: a GDSS for project analysis and evaluation. European Journal of Operational Research, 145 (2), 287-303.

Davis, T., 1993. Effective supply chain management. Sloan Management Review, 34 (4), 35-46.

Dixit, A. and Pindyck, R.S., 1994. Investment under uncertainty. Princeton University Press.

Doumpos, M. and Zopounidis, C., 2004. A multicriteria classification approach based on pairwise comparisons. European Journal of Operational Research, 158 (2), 378-389.

Drahovzal, O., 2006. Supply chain in electro-energetics and real options. Acta Polytechnica, 46 (4), 10-12.

Dyer, J.S., 1990a. Remarks on the analytic hierarchy process. Management Science, 36 (3), 249-258.

Dyer, J.S., 1990b. A clarification of 'Remarks on the analytic hierarchy process'. Management Science, 36 (3), $274-275$.

Excellence in view: a guide to the EFQM excellence model for the voluntary sector, 2009. National Council for Voluntary Organisations. Available from: http://www.ncvo-vol.org.uk/products-services/publications/excellence-in-view [Accessed 7 December 2009].

Figueira, J., Greco, S., and Ehrgott, M., eds., 2004. Multiple criteria decision analysis: state of the art surveys. New York, NY: Springer.

Figueira, J., Greco, S., and Ehrgott, M., 2005. Multiple criteria decision analysis: state of the art surveys. New York, NY: Springer.

Frode, K., 2007. A real option analysis of investments in hydropower: the case of Norway. Energy Policy, 35 (11), 5901-5908.

Geldermann, J., Spengler, T., and Rentz, O., 2000. Fuzzy outranking for environmental assessment. Case study: iron and steel making industry. Fuzzy Sets and Systems, 115 (1), 45-65.

Giménez, C. and Lourenço, H.R., 2008. e-SCM: internet's impact on supply chain processes. International Journal of Logistics Management, 19 (3), 309-343.

Goletsis, Y., et al., 2004. Automated ischemic beat classification using genetic algorithms and multicriteria decision analysis. IEEE Transactions on Biomedical Engineering, 51 (10), 1717-1725.

Gosain, S., Malhotra, A., and El Sawy, O.A., 2005. Coordinating for flexibility in e-business supply chains. Journal of Management Information Systems, 21 (3), 7-46.

Graham, T.S., Dougherty, P.J., and Dudley, W.N., 1994. The long term strategic impact of purchasing partnerships. International Journal of Purchasing and Materials Management, 30 (4), 13-18.

Greco, S., Matarazzo, B., and Słowinski, R., 2001. Rough sets theory for multicriteria decision analysis. European Journal of Operational Research, 129 (1), 1-47.

Grieger, M., 2003. Electronic marketplaces: a literature review and a call for supply chain management research. European Journal of Operational Research, 144 (2), 280-294.

Gunasekaran, A. and Ngai, E.W.T., 2004a. Virtual supply-chain management. Production Planning and Control, 15 (6), 584-595.

Gunasekaran, A. and Ngai, E.W.T., 2004b. Information systems in supply chain integration and management. European Journal of Operation Research, 159 (2), 269-295.

Harker, P.T. and Vargas, L.G., 1987. The theory of ratio scale estimation: Saaty's analytic hierarchy process. Management Science, 33 (11), 1383-1403.

Harker, P.T. and Vargas, L.G., 1990. Reply to 'Remarks on the analytic hierarchy process' by J. S. Dyer. Management Science, 36 (3), 269-273.

Ho, W., 2008. Integrated analytic hierarchy process and its applications - a literature review. European Journal of Operational Research, 186 (1), 211-228. 
Hobbs, B.F. and Meier, P., 2000. Energy decisions and the environment: a guide to the use of multicriteria methods. Massachusetts: Kluwer.

van Hoek, R., 2001. E-supply chains - virtually non-existing. Supply Chain Management: An International Journal, $6(1), 21-28$.

Hsieh, T.-Y., Lu, S.-T., and Tzeng, G.-H., 2004. Fuzzy MCDM approach for planning and design tenders selection in public office buildings. International Journal of Project Management, 22 (7), 573-584.

Hwang, C.L. and Lin, M.J., 1987. Group decision making under multiple criteria. Lecture Notes in Economics and Mathematical Systems, No. 281. Berlin: Springer.

Iz, P. and Gardiner, R.L., 1993. Analysis of multiple criteria decision support systems for cooperative groups. Group Decision and Negotiation, 2 (1), 61-79.

Jessup, L.M. and Valacich, J.S., 1993. Group support systems: new perspectives. New York, NY: Macmillan.

Johnson, M.E. and Whang, S., 2002. E-business and supply chain management: an overview and framework. Production and Operations Management, 11 (4), 413-423.

Joo, Y.-B. and Kim, Y.-G., 2004. Determinants of corporate adoption of e-marketplace: an innovation theory perspective. Journal of Purchasing and Supply Management, 10 (2), 89-101.

Ke, W., et al., 2009. How do mediated and non-mediated power affect electronic supply chain management system adoption? The mediating effects of trust and institutional pressures. Decision Support Systems, 46 (4), 839-851.

Keskinocak, P., et al., 2001. Decision support for managing an electronic supply chain. Electronic Commerce Research, $1(1-2), 15-31$.

Kim, S.H. and Ahn, B.S., 1999. Interactive group decision making procedure under incomplete information. European Journal of Operational Research, 116 (3), 498-507.

Kleindorfer, P.R., Kunreuther, H.C., and Schoemaker, P.J.H., 1993. Decision sciences: an integrative perspective. New York, NY: Cambridge University Press.

Koh, W.T.H., 1994. Making decisions in committees: a human fallibility approach. Journal of Economic Behavior and Organization, 23 (2), 195-214.

Liesiö, J., Mild, P., and Salo, A., 2007. Preference programming for robust portfolio modeling and project selection. European Journal of Operational Research, 181 (3), 1488-1505.

Lo, W.S., Hong, T.P., and Jeng, R., 2008. A framework of e-SCM multi-agent systems in the fashion industry. Production Economics, 114 (2), 594-614.

Lu, L. and Wang, G., 2008. A study on multi-agent supply chain framework based on network economy. Computers and Industrial Engineering, 54 (2), 288-300.

MacCrimmon, K.R., 1973. An overview of multiple objective decision making. In: J.L. Cochrance and M. Zeleny, eds. Multiple criteria decision making. Columbia, SC: University of South Carolina Press, 18-44.

Maier, P., 2010. How central banks take decisions: an analysis of monetary policy meetings. In: P.L. Siklos, M.T. Bohl, and M.E. Wohar, eds. Challenges in central banking. Cambridge University Press, 320-352.

Maloni, M.J. and Benton, W.C., 1997. Supply chain partnerships: opportunities for operations research. European Journal of Operational Research, 101 (3), 419-429.

Martel, J.M. and Roy, B., 2006. Analyse de la signifiance de diverses procédures d'agrégation multicritère. INFOR, 44 (3), 119-215.

Mason-Jones, R. and Towill, D., 1997. Enlightening supplies. Manufacturing Engineer, 76 (4), 156-160.

McGrath, R.G., 1997. A real options logic for initiating technology positioning investments. Academy of Management Review, 22 (4), 974-996.

Mukhtar, M., et al., 2009. A framework for analyzing e-supply chains. European Journal of Scientific Research, 25 (4), 649-662.

Nguyen, H.M. and Harrison, N.J., 2004. Electronic supply-chain orientation and its competitive dimensions. Production Planning and Control, 15 (6), 596-607.

Ngwenyama, O.K. and Brysona, N., 1999. Eliciting and mapping qualitative preferences to numeric rankings in group decision making. European Journal of Operational Research, 116 (3), 487-497.

Norese, M.F., 2006. ELECTRE III as a support for participatory decision-making on the localisation of waste-treatment plants. Land Use Policy, 23 (1), 76-85.

Perny, P., 1998. Multicriteria filtering methods based on concordance and non-discordance principles. Annals of Operations Research, 80, 137-167.

Phan, D.D., 2003. E-business development for competitive advantages: a case study. Information and Management, 40 (6), 581-590.

Poyhonen, M.A., Hamalainen, R.P., and Salo, A.A., 1997. An experiment on the numerical modelling of verbal ratio statements. Journal of Multi-Criteria Decision Analysis, 6 (1), 1-10.

Riabacke, M., et al., 2009. A prescriptive approach for eliciting imprecise weight statements in an MCDA process. In: F. Rossi and A. Tsoukias, eds. Algorithmic decision theory. Berlin: Springer-Verlag, 168-179.

Rios Insua, D. and French, S., 1991. A framework for sensitivity analysis in discrete multi-objective decision making. European Journal of Operational Research, 54 (2), 176-190.

Rogers, M. and Bruen, M., 1998. Choosing realistic values of indifference, preference and veto thresholds for use with environmental criteria within ELECTRE. European Journal of Operational Research, 107 (3), 542-551.

Roy, B., 1991. The outranking approach and the foundations of ELECTRE methods. Theory and Decision, 31 (1), 49-73.

Roy, B. and Bouyssou, D., 1993. Aide Multicritère à la Décision: Méthodes et Cas. Paris: Economica.

Rushton, A. and Oxley, J., 1991. Handbook of logistics and distribution management. London: Kogan Page. 
Saaty, T.L., 1977. A scaling method for priorities in hierarchical structures. Journal of Mathematical Psychology, 15 (3), 234-281.

Saaty, T.L., 1989. Decision making, scaling, and number crunching. Decision Sciences, 20 (2), 404-409.

Saaty, T.L., 1990a. How to make a decision: the analytic hierarchy process. European Journal of Operational Research, $48(1), 9-26$.

Saaty, T.L., 1990b. An exposition of the AHP in reply to the paper 'Remarks on the analytic hierarchy process'. Management Science, 36 (3), 259-268.

Saaty, T.L., 2006. Rank from comparisons and from ratings in the analytic hierarchy/network processes. European Journal of Operational Research, 168 (2), 557-570.

Saaty, T.L. and Sodenkamp, M., 2008. Making decisions in hierarchic and network systems. International Journal of Applied Decision Sciences, 1 (1), 24-79.

Salo, A.A., 1995. Interactive decision aiding for group decision support. European Journal of Operational Research, 84 (1), 134-149.

Smart, A., 2008. E-business and supply chain integration. Journal of Enterprise Information Management, 21 (3), $227-246$.

Stewart, G., 1995. Supply chain performance benchmarking study reveals keys to supply chain excellence. Logistics Information Management, 8 (2), 38-44.

Stockdale, R. and Standing, C., 2002. A framework for the selection of electronic marketplaces: a content analysis approach. Internet Research, 12 (3), 221-234.

Swafford, P.M., Ghosh, S., and Murthy, N., 2008. Achieving supply chain agility through IT integration and flexibility. International Journal of Production Economics, 116 (2), 288-297.

Tavana, M., 2006. A priority assessment multi-criteria decision model for human spaceflight mission planning at NASA. Journal of the Operational Research Society, 57 (10), 1197-1215.

The EFQM Excellence Model-Framework, 2009. British Quality Foundation. Available from: http://www.bqf.org.uk/ ex_framework.htm [Accessed 7 December 2009].

Toni, A.D., Nissmbeni, G., and Tonchia, S., 1994. New trends in supply environment. Logistics Information Management, $7(4), 41-50$.

Tsaur, S.H., Chang, T.Y., and Yen, C.H., 2002. The evaluation of airline service quality by fuzzy MCDM. Tourism Management, 23 (2), 107-115.

Vaidya, O.S. and Kumar, S., 2006. Analytic hierarchy process: an overview of applications. European Journal of Operational Research, 169 (1), 1-29.

Valls, A. and Torra, V., 2000. Using classification as an aggregation tool in MCDM. Fuzzy Sets and Systems, 15 (1), $159-168$.

Villani, G., 2008. An R\&D investment game under uncertainty in real option analysis. Computational Economics, $32(1-2), 199-219$.

Vincke, P., 1992. Multi-criteria decision-aid. Chichester: John Wiley.

Walker, W.E., 1988. Generating and screening alternatives. In: H.J. Miser and E.S. Quade, eds. Handbook of systems analysis: craft issues and procedural choices. Chichester: Wiley, 210-226.

Wang, J. and Hwang, W.-L., 2007. A fuzzy set approach for R\&D portfolio selection using a real options valuation model. Omega, 35 (3), 247-257.

Williams, L.R., Esper, T.L., and Ozment, J., 2002. The electronic supply chain: its impact on the current and future structure of strategic alliances, partnerships and logistics leadership. International Journal of Physical Distribution and Logistics Management, 32 (8), 703-719.

Wu, I.L. and Chuang, C.H., 2009. Analyzing contextual antecedents for the stage-based diffusion of electronic supply chain management. Electronic Commerce Research and Applications, 8 (6), 302-314.

Yager, R.R., 1977. Multiple objective decision-making using fuzzy sets. International Journal of Man-Machine Studies, 9 (4), 375-382.

Yang, J.B. and Xu, D.L., 2002. On the evidential reasoning algorithm for multiattribute decision analysis under uncertainty. IEEE Transactions on Systems, Man, and Cybernetics - Part A: Systems and Humans, 32 (3), 289-304.

Yen, B., Farhoomand, A., and Ng, P., 2004. Constructing an e-supply chain at Eastman Chemical Company. Journal of Information Technology, 19 (2), 93-107.

Yin, X.F. and Khoo, L.P., 2007. A hierarchical model for e-supply chain coordination and optimisation. Journal of Manufacturing Technology Management, 18 (1), 7-24.

Zadeh, L.A., 1965. Fuzzy sets. Information and Control, 8 (3), 338-353.

Zadeh, L.A., 1975. The concept of a linguistic variable and its application to approximate reasoning-I. Information Sciences, 8 (3), 199-249.

Zimmermann, H.J., 1991. Fuzzy set theory and its applications. 2nd ed. Boston, MA: Kluwer Academic Publishers.

\section{Appendix 1. Mathematical notations and definitions}

Let us introduce the following mathematical notations and definitions:

$\tilde{A}^{k}(f) \quad$ the individual fuzzy real option matrix of the e-SCM frameworks evaluated by the financial PC member $T_{h}(f)$

$\tilde{A}(f) \quad$ the fuzzy weighted collective real option matrix 
$C_{k l}^{T_{h_{i}}}(i)$

$C^{T_{h}}(i)$

$C(i)$

$\tilde{D}^{T_{h}}(i)$

$D_{k l}^{T_{h_{i}}}(i)$

$D^{T_{h}}(i)$

$D(i)$

$E(i)$

E

$E\left(\tilde{s}_{i, t_{j}}\right)$

$E\left(\tilde{x}_{i, t_{j}}\right)$

$F(i)$

$F_{i}$

$G(i)$

$m_{i}$

$n$

$n\left\{d_{1 i, t_{j}}\right\}$

$n\left\{d_{2 i, t_{j}}\right\}$

$q_{i}$

$\tilde{r}_{k j}^{T_{h}}(i)$

$r_{i}$

$\tilde{s}_{i, t_{j}}$

$\tilde{s}_{i, t_{j}}^{T_{h}(f)}$

$t_{l}$

$t_{1}$

$T_{1}(i)$

$T_{h}(i)$

$v_{h}(i)$

$\tilde{v}_{i, t_{j}}($ ro)

$\tilde{V}(f)$

$w_{1}(i)$

$w_{j}(i)$

$x_{j}(i)$

$\tilde{x}_{i, t_{j}}$

$\tilde{x}_{i, t_{j}}^{T_{h}(f)}$

$\delta_{i}$

$\sigma_{i, t_{j}}^{2}$ the concordance set of $F_{k}$ and $F_{l}$ for the $i$ th enabler's criterion evaluated by the PC member $T_{h}(i)$ the individual concordance matrix for the $i$ th enabler's criterion evaluated by the PC member $T_{h}(i)$ the weighted collective concordance matrix for the $i$ th enabler's criterion the fuzzy individual ordinal rank matrix for the $i$ th enabler's criterion the discordanceset of $F_{k}$ and $F_{l}$ for the $i$ th enabler's criterion evaluated by the PC member $T_{h}(i)$ the individual discordancematrix for the $i$ th enabler's criterion evaluated by the PC member $T_{h}(i)$ the weighted collective discordance matrix for the $i$ th enabler's criterion the aggregate dominance matrix for the $i$ th enabler's criterion the collective aggregate dominance matrix the possibilistic mean value of the weighted collective present value of expected payoffs of the $i$ th e-SCM framework at time $t_{j}$

the possibilistic mean value of the weighted collective expected costs of the $i$ th e-SCM framework at time $t_{j}$

the concordance dominance matrix for the $i$ th enabler's criterion

the $i$ th e-SCM framework

the discordancedominance matrix for the $i$ th enabler's criterion

the number of subcriteria of the $i$ th enabler's criterion

the number of alternative e-SCM frameworks

the $i$ th e-SCM frameworkcumulative normal probability distribution for $\left\{d_{1 i, t_{j}}\right\}$

the $i$ the-SCM framework cumulative normal probability distribution for $\left\{d_{2 i, t_{j}}\right\}$

the number of the PC members of the $i$ th enabler's criterion

the fuzzy ordinal rank of the $k$ th e-SCM framework with respect to the $j$ th subcriterion for the $i$ th enabler's criterion evaluated by the PC member $T_{h}(i)$

the risk-free interest rate

the weighted collective fuzzy present value of the expected payoffs of the $i$ th e-SCM framework at time $t_{j}$

the individual fuzzy present value of the expected payoffs of the $i$ th e-SCM framework at time $t_{j}$ evaluated by the financial PC member $T_{h}(f)$

the maximum deferral time of the e-SCM frameworks

the minimum deferral time of the e-SCM frameworks

the $i$ th PC leader

the $h$ th PC member

the voting power of the $h$ th PC member of the $i$ th enabler's criterion

the fuzzy real option value of the $i$ th e-SCM framework at time $t_{j}$

the fuzzy real option value matrix

the importance weight of the $i$ th enabler's criterion

the importance weight of the $j$ th subcriterion of the $i$ th enabler's criterion

the $j$ th subcriterion of the $i$ th enabler's criterion

the weighted collective fuzzy present value of the expected cost of the $i$ th e-SCM framework at time $t_{j}$

the individual fuzzy present value of the expected cost of the $i$ th e-SCM framework at time $t_{j}$ evaluated by the financial PC member $T_{h}(f)$

the value loss over the duration of the option

the variance of the weighted collective fuzzy present value of the expected payoffs of the $i$ th e-SCM framework at time $t_{j}$ evaluated by the financial PC member $T_{h}(f)$ 